International Journal of Mechanical Engineering and Technology (IJMET)

Volume 12, Issue 4, April 2021, pp. 1-24. Article ID: IJMET_12_04_001

Available online at https://iaeme.com/Home/issue/IJMET?Volume $=12 \&$ Issue $=4$

ISSN Print: 0976-6340 and ISSN Online: 0976-6359

DOI: https://doi.org/10.34218/IJMET.12.4.2021.001

(C) IAEME Publication

Scopus Indexed

\title{
EXPERIMENTAL INVESTIGATION ON SOLAR PARABOLIC TROUGH COLLECTOR PERFORMANCE USING GRAPHENE AND TITANIUM OXIDE NANOFLUIDS UNDER FORCED CIRCULATION
}

\author{
R. Vasanthi \\ Research Scholar, YSR Engineering College, Yogi Vemana University, \\ Andhra Pradesh, India \\ G. Jaya Chandra Reddy \\ Professor, Yogi Vemana University, Andhra Pradesh, India
}

\begin{abstract}
Experiments were conducted on a solar parabolic trough collector (PTC) with graphene oxide (GO) nanofluid and Titanium oxide $\left(\mathrm{TiO}_{2}\right)$ nanofluid as the working fluids, circulated forcibly with the aid of a pump. The PTC had a collector area of 2.3 $\mathrm{m}^{2}$, a concentric tube heat exchanger (CTHX) and a storage tank. The GO and $\mathrm{TiO}_{2}$ nanofluids was prepared by ultrasonication of the $\mathrm{GO}$ nanoparticles and $\mathrm{TiO}_{2}$ nanoparticles with de-ionized (DI) water as the base fluid, without adding any surfactant. Homogeneous and stable $\mathrm{GO}$ and $\mathrm{TiO}_{2}$ nanofluids for five different mass concentrations, $(\phi)=0.05,0.1,0.2,0.3$ and 0.5 , were prepared. The nanofluids were found to be stable for 60 days without any sedimentation issues. The thermo-physical properties of the $\mathrm{GO}$ and $\mathrm{TiO}_{2}$ nanofluids, such as the thermal conductivity, viscosity, density and specific heat, were estimated. For the flow supplied by the pump, the maximum value of the PTC inlet pipe and fluid property-based Reynolds number was found to be 4400. The PTC's overall heat transfer co-efficient ( $h$ ), friction factor and collector efficiency were investigated for $\mathrm{GO}$ and $\mathrm{TiO}_{2}$ nanofluids under laminar conditions. It was observed that for GO nanofluid with $\phi=0.5$ and a flow rate of 0.05 $\mathrm{kg} / \mathrm{s}$, the enhancement in the collector efficiency was $16.3 \%$ over that of the $\mathrm{TiO}_{2}$ nanofluid and base fluid (DI water). The collector efficiency was found to increase with increasing " $\phi$ " and flow rate. The increment in heat transfer co-efficient $(h)$ for the GO nanofluid with $\phi=0.1,0.2$ and 0.3 were $7.03 \%, 8.93 \%$ and $11.5 \%$, respectively and for $\mathrm{TiO}_{2}$ nanofluid with $\phi=0.1,0.2,0.3$ and 0.5 were $5.08 \%, 7.98 \%, 8.12 \%$ and $11.2 \%$.
\end{abstract}

Keywords: Parabolic trough collector, Laminar flow, Collector efficiency, Graphene oxide nanofluid, Titanium oxide nanofluid, Heat transfer coefficient. 
Experimental Investigation on Solar Parabolic Trough Collector Performance using Graphene and Titanium Oxide Nanofluids Under Forced Circulation

Cite this Article: R. Vasanthi and G. Jaya Chandra Reddy, Experimental Investigation on Solar Parabolic Trough Collector Performance using Graphene and Titanium Oxide Nanofluids Under Forced Circulation, International Journal of Mechanical Engineering and Technology (IJMET), 12(4), 2021, pp. 1-24. https://iaeme.com/Home/issue/IJMET?Volume=12\&Issue $=4$

\section{INTRODUCTION}

Industries such as power generation, air conditioning, microelectronics and cooling systems use conventional fluids such as water, ethylene glycol (EG) and transformer oil as heat transfer fluids. The poor thermal conductivity ( $\mathrm{k}$ ) of these fluids greatly limits their heating and cooling role in heat exchangers [1]. Hence, it is essential to enhance or improve the heat transfer capabilities of the working fluids. The advances in nanotechnology have resulted in the development of a class of fluids termed nanofluids. Nanofluids, prepared by dispersing rods or tube-shaped nanoparticles in a base fluid, have gained attention because of their increased thermal conductivity [2-4], which translates to lower operating costs, higher energy efficiency and better performance [5-10]. Recently, significant research has been conducted on the use of carbon-based nanostructure materials to prepare nanofluids because of their super thermal conductivity properties. Carbon nanostructures have higher thermal conductivity than other nanoparticles because of their large intrinsic thermal conductivity and low density [11]. A significant number of studies have been conducted on the use of carbon-based nanostructures such as carbon nanotubes [12], single-wall carbon nanotubes [13], multi-walled carbon nanotubes (MWCNT) [14], graphite [15], graphene oxide (GO) [16], and graphene [17] to prepare nanofluids. Novoselov et al. [18] first discovered graphene, which gained attention because of its unique chemical and physical properties and two-dimensional structure. The value of a single layer of graphene at room temperature is estimated to be in the range of 2000 $5200 \mathrm{~W} / \mathrm{m} \mathrm{K}$. Balandin et al. [19] reported a maximum thermal conductivity value of single layer graphene as $5300 \mathrm{~W} / \mathrm{m} \mathrm{K}$, which is notably higher than that of carbon nanotubes. Methods such as Hummer's method, the modified Hummer's method and chemical vapor deposition can be used for the synthesis of GO, and these authors adopted chemical methods to improve the yield.

The aqueous suspensions of stable homogeneous graphene nano platelet (GNP) nanofluids were normally prepared by high-power ultrasonication. The stability and the thermo-physical properties of GNPs have been reported previously by Mehrali et al. [20]. Jyothirmayee and Ramaprabhu [21] performed an experimental study on the enhanced convective heat transfer of graphene water nanofluids. For a $0.05 \%$ concentration, they reported $16 \%$ and $64 \%$ enhancements in thermal conductivity at $25^{\circ} \mathrm{C}$ and $50^{\circ} \mathrm{C}$, respectively. Yarmand et al. [22] conducted experimental studies on thermal conductivity, the viscosity, the Nusselt number and the heat transfer coefficient (h) in the turbulent flow of GNP-Ag/water nanofluids in a pipe at a constant heat flux. Ahmad Ghozatloo et al. [23] experimentally studied the performance of heat transfer coefficient (h) with graphene nanofluids in a shell and tube heat exchanger and found that the values increased by up to $35.6 \%$ at $38^{\circ} \mathrm{C}$ with a concentration of $0.1 \mathrm{wt} . \%$ when compared to pure water. Mehrali et al. [24] also investigated the heat transfer and entropy generation for the laminar forced convection flow of GNP nanofluids in a horizontal tube and found that the thermal conductivity increases from $12 \%$ to $28 \%$ as the nanofluid temperature increases and the heat transfer co-efficient increases by 15\%. Zanjani et al. [25] conducted experimental studies on the laminar forced convective heat transfer of a GO nanofluid inside a circular tube and obtained an increase in the values of thermal conductivity of $10.3 \%$ and heat transfer coefficient (h) of $14.2 \%$ for a Reynolds number of 1850 with 0.02 volume concentration. Amiri et al. [26] conducted an experimental study on thermo-physical properties 
of graphene nano platelet-based water nanofluids and studied the covalent and non-covalent functionalization effects on the thermal conductivity, viscosity, and thermosyphon performance for various operating temperatures and concentrations. It was observed from the results that thermophysical property of covalent nanofluids (GNP-COOH/water) was more enhanced compared to those of non-covalent nanofluids (GNP-SDBS/water) and water. Overall heat transfer and thermal efficiency showed significant increases for covalent nanofluids at low concentrations. Sadeghinezhad et al. [27] reviewed the effective parameters on the thermal and rheological properties, forced convective heat transfer, pool boiling, critical heat flux and optical properties of graphene nanofluids. The results show that the thermal conductivity of graphene nanofluid is influenced by nanoparticle concentration, size, shape, base fluid, temperature, additives and acidity. A review of nanofluids on the applications of solar energy for different types of solar collectors [28-30], solar water heaters, solar still, solar photovoltaic systems were presented. In addition to the literature being discussed here, it can be observed that a GO nanofluid has not been tested so far in a solar thermal energy device such as a parabolic trough collector (PTC). Few works were reported by researchers in the area of boiling $[16,27]$, convective heat transfer coefficient $[17,20]$ and heat exchangers $[18,23]$ with a GO nanofluid. Hence, the objective of this work is to conduct performance studies on an PTC used for solar water heating with a GO nanofluid equipped with a concentric double pipe heat exchanger (CTHX) for utility water heating. As discussed earlier, the GO nanofluid was chosen for its high thermal and electrical properties. The GO particles were synthesized, and the thermo-physical properties of the GO nanofluid were found by suitable instruments.

\section{EXPERIMENTAL METHODS AND INSTRUMENTATION}

The experiments were conducted on a solar PTC procured from Ecosense Insight solar pvt Ltd is shown in fig 1 . The solar trough collector experiment was performed in Lakireddy balireddy college of engineering, mylavaram, India, and the latitude and longitude of the test location were $16^{\circ} .31^{\prime} \mathrm{N}$ and $80^{\circ} .39^{\prime} \mathrm{E}$, respectively. The solar collector setup was placed in the outdoor facing solar noon position. The outer surface temperature was measured using a surface thermocouple sensors fixed at locations $25,50,75,100,125$, and $150 \mathrm{~cm}$ from the inlet. For the study of $\mathrm{GO}$ and $\mathrm{TiO}_{2} / \mathrm{DI}-\mathrm{H}_{2} \mathrm{O}$ nanofluid was the preferred cyclic heat transfer fluid, which was stored in a liquid tank and then pumped to the absorber tube entrance using a pump, at a flow rate of $0.0086-0.060 \mathrm{~kg} / \mathrm{s}$ and a accuracy of $\pm 1 \%$. The outlet of the absorber tube was integrated with a heat exchanger to reduce the temperature of nanofluids, making it viable for recycling. Although the heat exchanger could reduce the temperature up to $4^{\circ} \mathrm{C}$, it was not sufficient to run the test as per ASHRAE standards, Hence, a constant temperature bath was used to sustain the stability of nanofluid temperature with respect to ambient conditions. The system contained a receiver tube with tracking and the collector was positioned perpendicular to the noon solar, and the thermal performance was studied by concentration method. Parameters such as solar radiation, wind velocity, ambient temperature, flow rate, test section of entry/exit temperatures, and gradient pressure values were recorded. The solar radiation was measured using a SP Lite 2 silicon pyranometer; wind velocity and ambient temperatures were measured using a vane-type anemometer with a range of 0-25 m/s, accuracy $\pm 3 \%( \pm 0.22 \mathrm{~m} / \mathrm{s})$, and operating humidity about $80 \%$. The accuracies of rotameter, temperature sensor, and pyranometer were $\pm 5 \%, \pm 0.1^{\circ} \mathrm{C}$, and $\pm 6.25 \%$, respectively. The entire solar PTC test facility was mounted in the outdoor at ambient conditions and average wind velocity of $1-10 \mathrm{~m} / \mathrm{s}$. The detailed specifications of the solar PTC are shown in Table-1. 
Experimental Investigation on Solar Parabolic Trough Collector Performance using Graphene and Titanium Oxide Nanofluids Under Forced Circulation
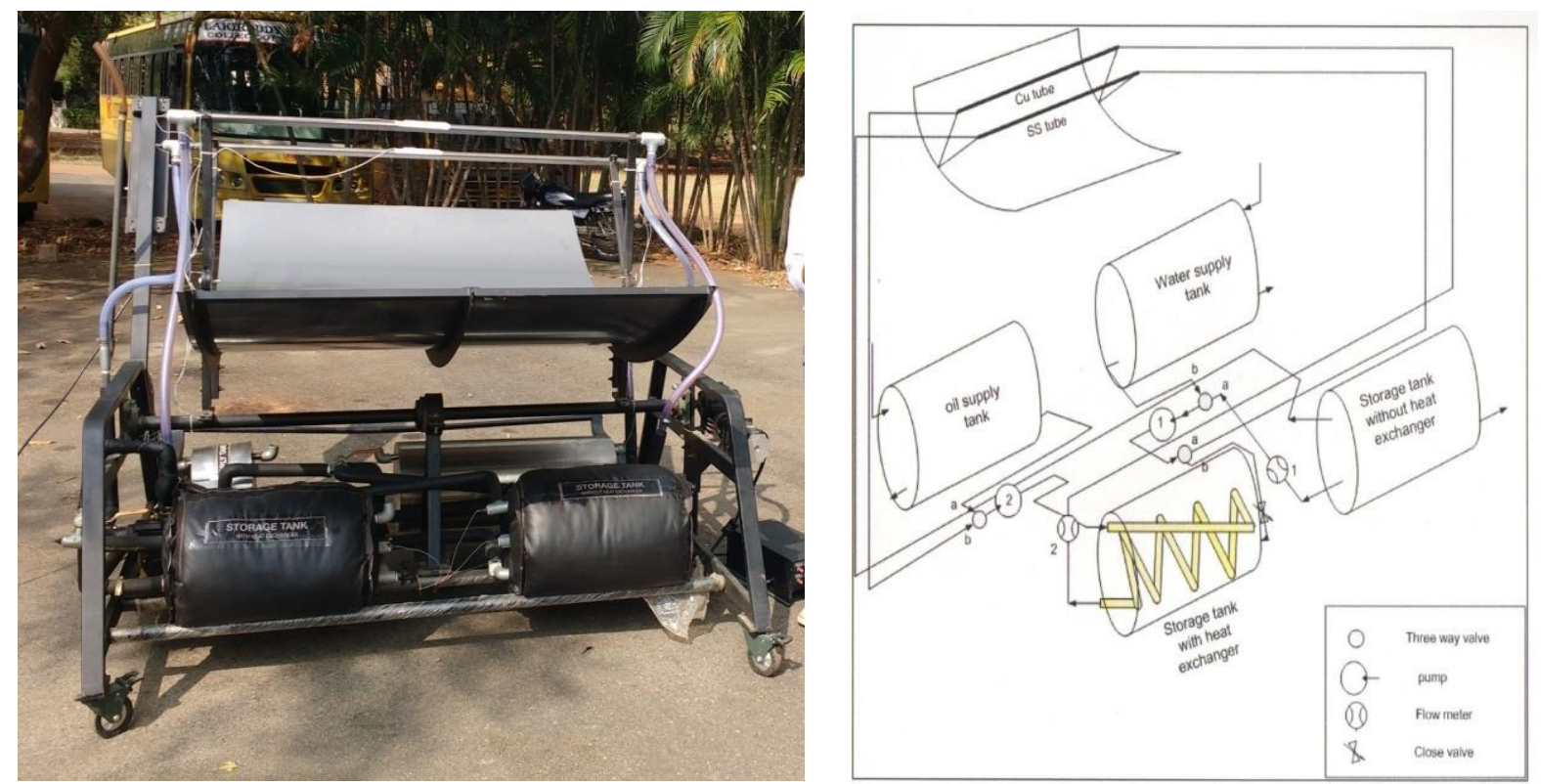

Figure 1 Solar Parabolic Trough Collector

Table 1 Specifications of the PTC set up

\begin{tabular}{|c|c|c|}
\hline S.No & Components & Specifications \\
\hline \multirow[t]{13}{*}{1} & Heat generating unit with tracking system & \\
\hline & Parabolic reflector & \\
\hline & Length & $4 \mathrm{ft}$ \\
\hline & Arc length (perimeter) & $6 \mathrm{ft}$ \\
\hline & Depth & $0.68 \mathrm{ft}$ \\
\hline & Focal length & $1.99 \mathrm{ft}$ \\
\hline & Material & SS with mirror film \\
\hline & Sun tracker & Single axis \\
\hline & Absorber tube & \\
\hline & Length & $4 \mathrm{ft}$ \\
\hline & Diameter & 1 inch \\
\hline & Absorber material & Copper, SS \\
\hline & Piping material & GI and Copper \\
\hline \multirow[t]{9}{*}{2} & Storage unit & \\
\hline & Supply tanks & \\
\hline & Capacity & 46 ltrs \\
\hline & Material & SS \\
\hline & Storage tanks & \\
\hline & Capacity & 28 ltrs \\
\hline & Material & SS \\
\hline & Insulation used & Glass wool with rexene \\
\hline & Working fluid & Water \\
\hline \multirow[t]{3}{*}{3} & Control unit & \\
\hline & Pump power rating & $\mathrm{HP}$ \\
\hline & Head & $6 \mathrm{~m}$ \\
\hline
\end{tabular}




\subsection{Nanofluid Preparation}

\subsubsection{Synthesis of graphene oxide \& titanium dioxide nanofluid}

The experimental tests on the solar PTC were conducted using synthesized GO and $\mathrm{TiO}_{2}$ nanofluids as the solar thermal energy absorber fluid. For this study, distilled water (DI) water based $\mathrm{GO}$ and $\mathrm{TiO}_{2}$ nanofluid was used as a heat transfer fluid. Commercially available GO and $\mathrm{TiO}_{2}$ nano-powders (nano wings, India) of $99.5 \%$ purity with an average particle diameter of $40-50 \mathrm{~nm}$ was procured. Different test nanofluids at concentrations of $0.01 \%, 0.02 \%, 0.03 \%$, and $0.04 \%$ were prepared by dispersing the nano-powder in DI water. To prevent agglomeration and sedimentation of $\mathrm{GO}$ and $\mathrm{TiO}_{2}$ nanoparticles, ultrasonic bath sonication were used, and a $\mathrm{pH}$ value of 7 was maintained for the nanofluid solution. The thermophysical properties of $\mathrm{GO} / \mathrm{DI}-\mathrm{H}_{2} \mathrm{O}, \mathrm{TiO}_{2} / \mathrm{DI}-\mathrm{H}_{2} \mathrm{O}$ nanofluid were compared between theoretical and experimental values and presented in Table 2.
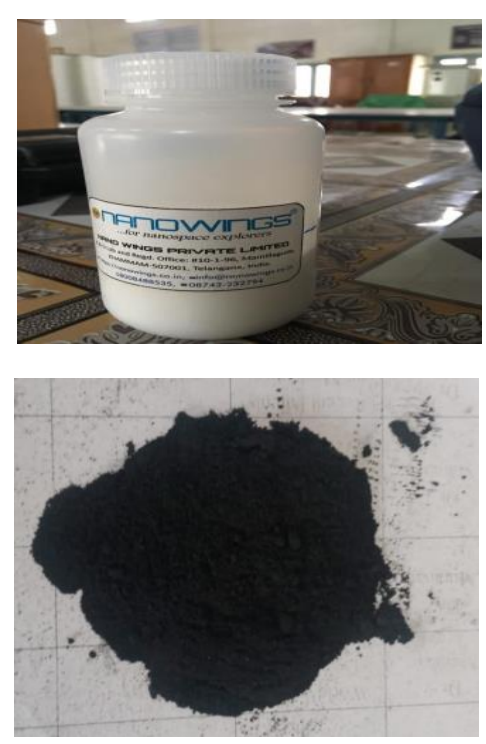
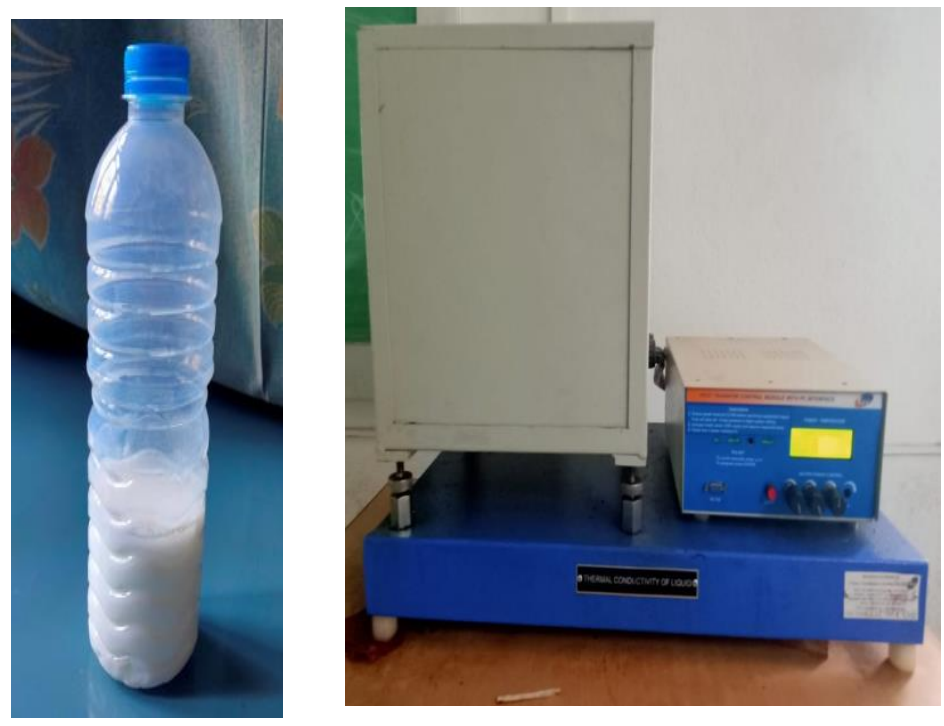

Figure $2 \mathrm{GO} \& \mathrm{TiO}_{2}$ nanofluid, Guarded Hot Plate Assembly

\subsection{Thermophysical Properties of Nanofluids}

To further study the characterization and quality assessment of the nanofluid, it is necessary to estimate the transport behavior of the absorber fluid to be used in the PTC.

\subsubsection{Thermal Conductivity}

The thermal conductivity of the GO nanofluid suspension was measured using a Guarded Hot Plate Assembly. The thermal conductivity of the GO nanofluid is depicted in Fig. 2. The thermal conductivity increases with an increase in the temperature and with the nanofluid concentrations, and this behavior is similar to that reported by Choi et al., [33] and Rashmi and Ramaprabhu [34]. The increase in the thermal conductivity is due to the Brownian motion of the particles, which is explained in Brownian theory [35]. The second phenomenon that influences the thermal conductivity is the percolation network effect, which occurs because the larger sized GO particles form a chain-like structure, resulting in the effective transport of heat, explained in detail by percolation theory [36]. For $\phi=0.5$ the enhancement in thermal conductivity is from 11.2 to 19.3 whereas it is from 1.58 to 6.71 for Kamatchi et al. [42] for the temperature range of $30-70^{\circ} \mathrm{C}$. For $\phi=0.5$, k enhancement varies from 14 to 17.5 for temperature varying from 10 to $60^{\circ} \mathrm{C}$ as reported by Ahmad Ghozatloo et al.[23] . 
Experimental Investigation on Solar Parabolic Trough Collector Performance using Graphene and Titanium Oxide Nanofluids Under Forced Circulation
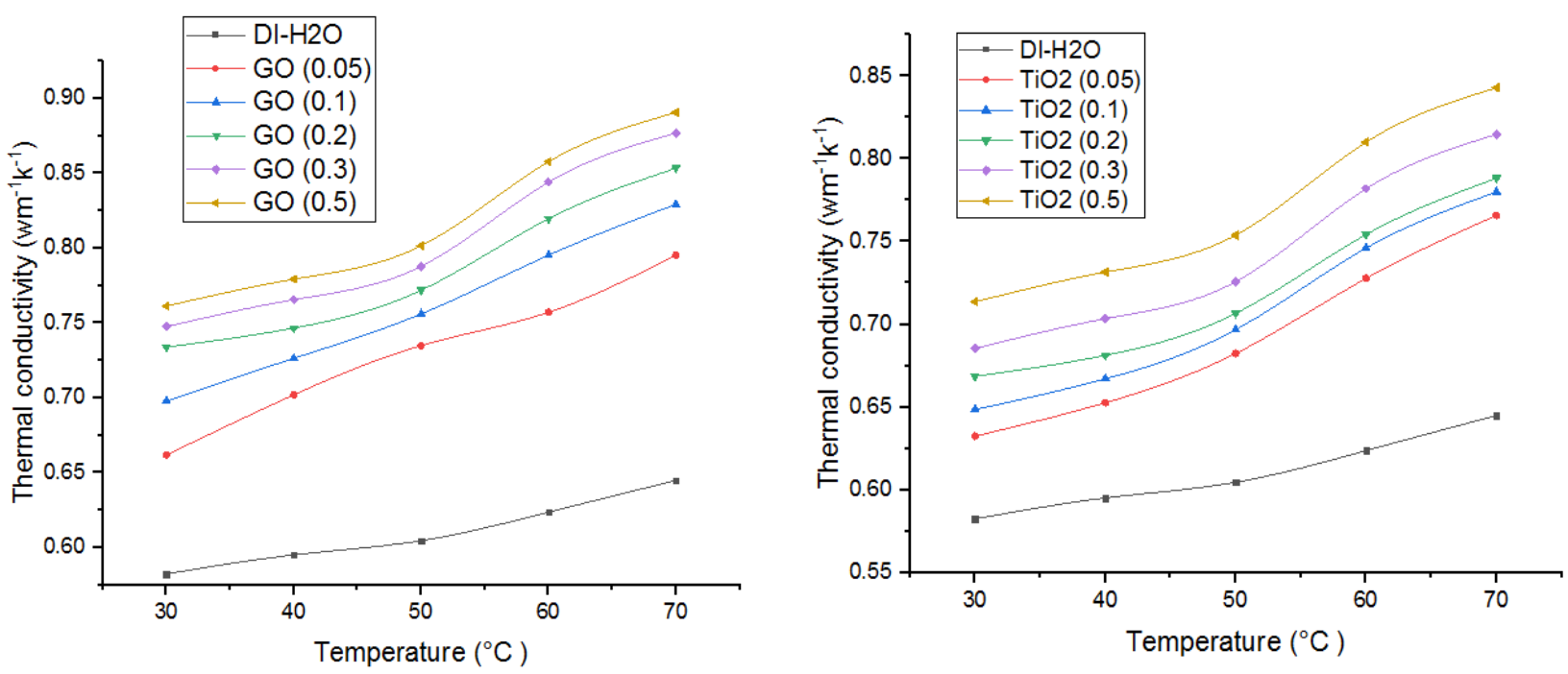

Figure 3 Effect of temperature on the thermal conductivity of $\mathrm{GO} \& \mathrm{TiO}_{2}$ nanofluid.

\subsubsection{Viscosity}

The rheological behavior of the GO nanofluid was measured for different mass concentrations of 0.05 and 0.5 and at different temperatures ranging from 30 to $50^{\circ} \mathrm{C}$. The results reveal that for $\phi=0.05$, there is a decrease in the viscosity Fig. 4 shows the effect of temperature on the viscosity of the base fluid and the GO nanofluid at different values of $\phi$. The viscosity was found to show a decreasing trend for all fluids with an increase in temperature. Compared to the base fluid, the viscosity of the nanofluids was found to increase with $\phi=0.5$ by $10.4 \%$ at $50^{\circ} \mathrm{C}$ to $20.2 \%$ at $30^{\circ} \mathrm{C}$, which indicated that the viscosity decreased with an increase in temperature.
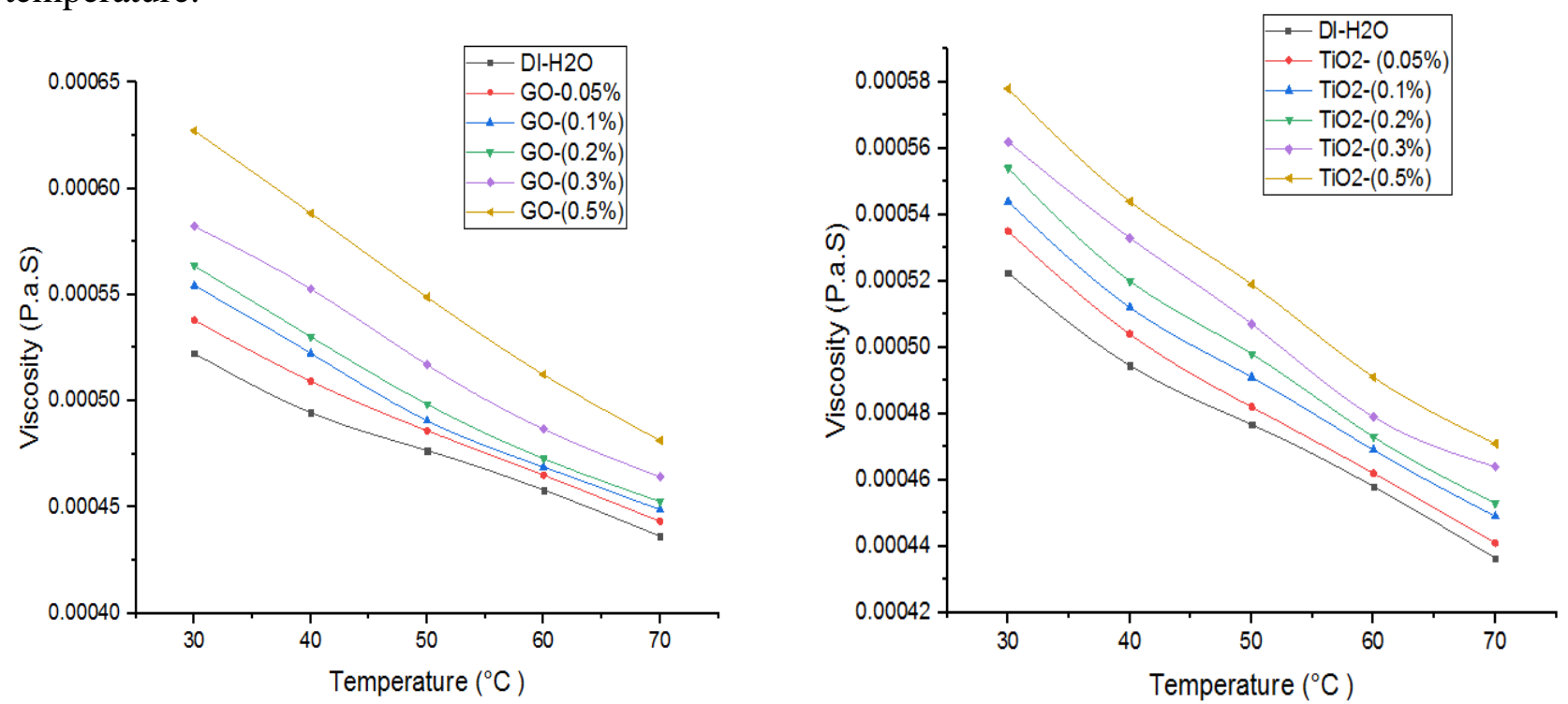

Figure 4 Effect of the viscosity on the temperature of $\mathrm{GO} \& \mathrm{TiO}_{2}$ nanofluid.

\subsubsection{Density}

The density $(\rho)$ of the nanofluids was estimated by measuring the mass of the known volume of the nanofluid, taken in a measuring jar. The estimated values of the GO nanofluid density at different concentrations are shown in Table 2. It was observed that as the concentration 
increases the density slightly decreases because of the fact that the density of graphene oxide suspended in water is lower than the density of the base fluid.

Table 2 Density of $\mathrm{GO} \& \mathrm{TiO}_{2}$ nanofluids at different concentrations

\begin{tabular}{|c|c|c|c|}
\hline S.No & Concentration by mass $(\boldsymbol{\phi})$ & $\begin{array}{c}\text { Density }\left(\mathbf{k g} / \mathbf{m}^{\mathbf{3}}\right) \\
\mathbf{G O}\end{array}$ & $\begin{array}{c}\text { Density }\left(\mathbf{k g} / \mathbf{m}^{\mathbf{3}}\right) \\
\mathbf{T i O}_{\mathbf{2}}\end{array}$ \\
\hline 1 & 0.05 & 923.4 & 902.5 \\
\hline 2 & 0.1 & 865.3 & 834.3 \\
\hline 3 & 0.2 & 878.6 & 845.9 \\
\hline 4 & 0.3 & 886.4 & 862.3 \\
\hline 5 & 0.5 & 898.6 & 884.2 \\
\hline
\end{tabular}

The generalized thermophysical properties of nanofluid were arrived as:

Wasp model for Thermal Conductivity [26] $\left(\mathrm{K}_{n f}\right)$ expressed as:

$$
K_{n f}=K f \frac{K P+2 k f-2 \alpha(K f-K P)}{K P+2 k f+\alpha(K f-K P)}
$$

Brinkman Model for Viscosity [27] $\left(\mu_{n f}\right)$ expressed as:

$$
\frac{\mu_{n f}}{\mu_{f}}=\frac{1}{(1-\varepsilon P)^{2.5}}=\frac{1}{\left(1-\emptyset^{2.5}\right)}
$$

Pak and Xuan Model for Density [28] ( $\left.\rho_{\text {nf }}\right)$ expressed as:

$$
\rho_{n f}=(1-\emptyset) \rho_{b f}+\emptyset \rho_{p}
$$

Pak and Cho Specific Heat [29] $\left(\mathrm{CP}_{\mathrm{nf}}\right)$ expressed as:

$$
C P_{n f}=\frac{(1-\varnothing) \rho_{b f} C p_{b} f+\emptyset \rho_{p} C P_{p}}{\rho_{b f}}
$$

Experiments with the solar PTC involving GO/DI- $\mathrm{H}_{2} \mathrm{O}$ and $\mathrm{TiO}_{2}-\mathrm{DI}-\mathrm{H}_{2} \mathrm{O}$ nanofluid were conducted between March and June 2020 (10 a.m. to 4 p.m.) during clear sunny days. Different concentrations of nano-powders $(0.05 \%, 0.1 \%, 0.2 \%, 0.3 \%$ and $0.5 \%)$ and mass flow rates $(0.0092,0.0157,0.046$, and $0.05 \mathrm{~kg} / \mathrm{s})$ were employed. Each test consisted of six test cycles, where each cycle took around $60 \mathrm{~min}$. Furthermore, each test cycle had subsections (15 min each) based on the quasi-steady-state conditions and the collector time constant, equal to $63.2 \%$, as per [23] standards. From among the tests conducted across several months, the best test data were chosen based on consistent track results. Because of climate change and weather ambiguity, multiple tests were conducted. Experiments were carried out based on the ASHRAE test procedures, as follows:

- Direct beam irradiance was greater than $800 \mathrm{~W} / \mathrm{m}^{2}$.

- Radiation from clear sky with a time interval of 10 min was $\pm 34 \mathrm{~W} / \mathrm{m}^{2}$.

- Wind velocity $=3-4 \mathrm{~m} / \mathrm{s}$ for a natural wind flow.

- Inlet working fluid temperature was less than or equal to $\pm 10^{\circ} \mathrm{C}$ toward ambient temperature.

- Heat transfer flow rate for working fluid $=0.02 \mathrm{~kg} / \mathrm{s}\left(\mathrm{m}^{2}\right)$ 
Experimental Investigation on Solar Parabolic Trough Collector Performance using Graphene and Titanium Oxide Nanofluids Under Forced Circulation

Investigations focused on four important parameters such as solar time constant, incident angle modifier (IAM), outlet temperature, and collector efficiency.

\subsection{Solar Time Constant and Incident Angle Modifier (IAM)}

Solar time constant is a transient behavior that determines the time intervals for the quasisteady-state of the solar collector. The time period for stabilization of heat transfer in the solar PTC was recorded Figure 5a \& 5b. When the collector time constant reached 63.2\% of Eq. (5), the system was said to be stable. The time constants for the PTC were determined for various nanofluid concentrations, which were 256, 298, 312, 412, and $506 \mathrm{~s}$ :

$$
\left(T_{o}-T_{i}\right)=0.632\left(T_{f o, s s}-T_{i}\right)
$$

where $T_{o}$ is outlet temperature of working fluid, $T_{i}$ is inlet temperature of working fluid, $\mathrm{T}_{f o, s s}$ is steady-state working fluid outlet temperature. Incident Angle Modifier was determined by dividing the instantaneous collector efficiency at a specific value of angle of incidence $(0-$ $60^{\circ}$ ) by the peak efficiency of the solar PTC. It was derived by ASHRAE [23] standards. A correlation was obtained for the incidence angle using curve fitting (third order polynomial) as in Eq. (6). The coefficient of determination (R2) of the correlation was found to be 0.998 . The resulting equation was:

$$
K_{\alpha \tau}=0.000000774 \theta^{3}-0.000148 \theta^{2}-0.00320 \theta+0.979
$$
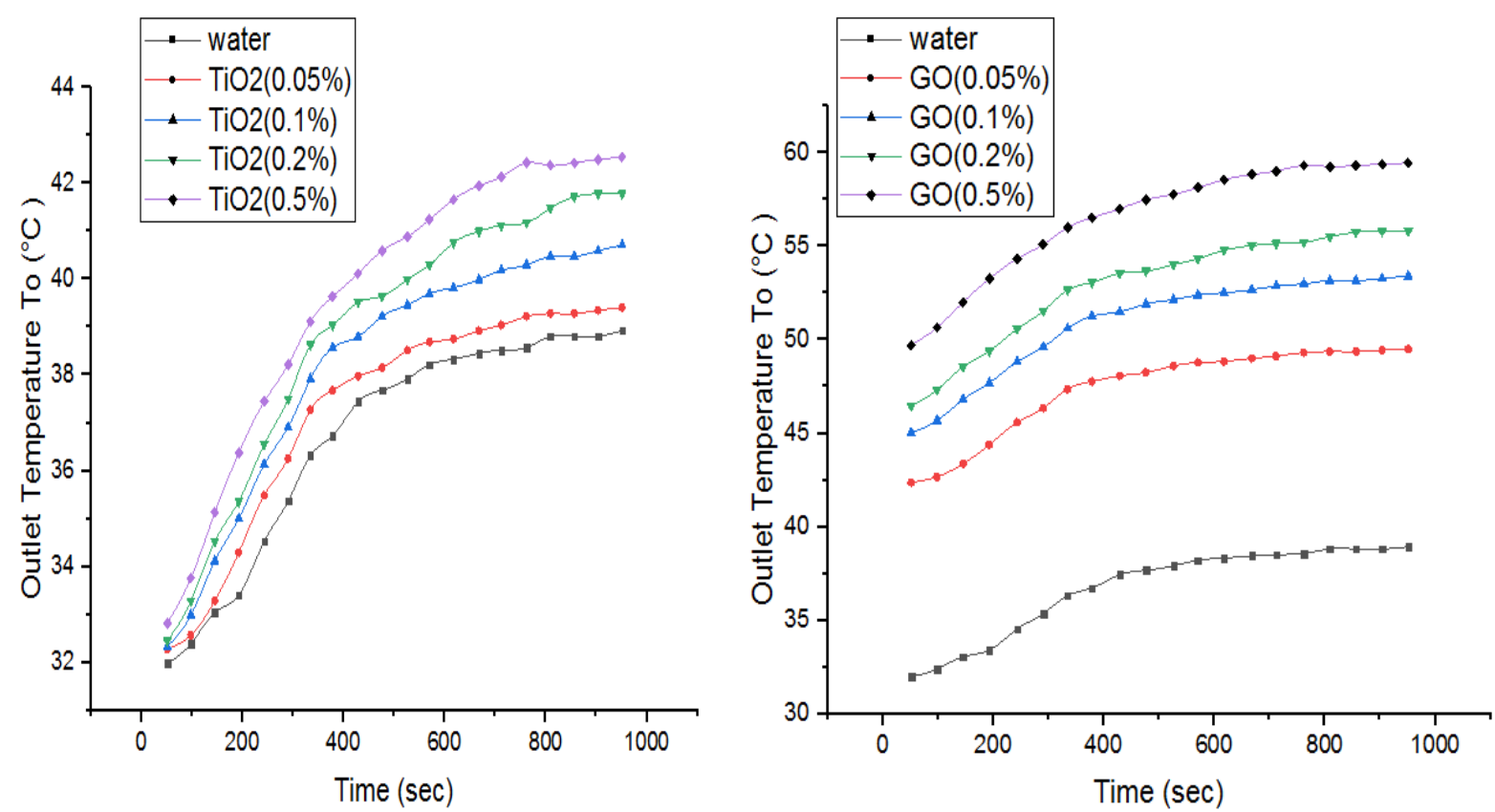

Figure 5a \& 5b Comparison of collector's time constants for various nanofluid concentrations

\subsection{Estimation of Collector Efficiency}

The PTC operating under steady-state conditions and its performance are discussed in this section. The collector instantaneous efficiency describes the useful heat gain to the entire incident radiation intercepted by the collector aperture surface area given by Eq. (7-9). The 
useful heat gain by the working fluid from the receiver tube of the solar PTC was calculated based on the literature [24,25]:

$$
Q_{\text {in }}=m C_{P n f}\left(T_{o}-T_{i}\right)
$$

The collector efficiency of the solar PTC was obtained based on [24,25]:

$$
\eta_{c}=\frac{Q_{i n}}{A_{a} I}=\frac{m C_{P n f}\left(T_{o}-T_{i}\right)}{A_{a} I}
$$

A series of experiments were conducted and the results plotted to obtain the efficiency curve of the solar PTC using linear fit method. The efficiency of the collector was given by

$$
\begin{aligned}
& \eta_{c}=F_{R} \eta_{o}-\frac{F_{R} U_{L}}{C}\left(\frac{\left(T_{i}-T_{a}\right)}{I}\right) \\
& F_{R}\left(\eta_{0}\right)=F_{R}(\tau \alpha): \text { a- Absorbed energy parameter (Intercept) } \\
& \frac{F_{R} U_{L}}{C}: \text { b- Removal energy parameter (slope) and C- Concentration ratio } \\
& \left(\frac{\left(T_{i}-T_{a}\right)}{I}\right): \text { Reduced temperature parameter (or) characteristics curve of collector. }
\end{aligned}
$$

\subsection{Data Reduction}

Convective heat transfer coefficient, Nusselt number, friction factor, and collector efficiency were the four significant factors determining the efficiency of the solar PTC. Reynolds number for the solar PTC was expressed as [30,31]:

$$
R e=\left(\frac{\rho_{n f} u d_{i}}{\mu_{n f}}\right)
$$

where $\mathrm{d}_{i}$ is inner diameter of receiver tube $(\mathrm{m}), \rho_{n f}$ is density of nanofluid, and $\mu_{n f}$ is viscosity of nanofluid. The average heat transfer coefficient for the solar PTC was given by:

$$
h_{n f}=\left(\frac{Q_{i n}}{A_{a}\left(T_{w}-T_{b}\right)}\right)
$$

where $T_{w}$ is mean wall temperature of absorber tube and $T_{b}$ is bulk mean temperature of nanofluids given by $T_{b}=\left(T_{i}+T_{o}\right) / 2$. Temperature gradient was given by $\Delta T=\left(T_{w}-T_{b}\right)$. 
Experimental Investigation on Solar Parabolic Trough Collector Performance using Graphene and Titanium Oxide Nanofluids Under Forced Circulation

$\mathrm{Tw}=\Sigma\left(\mathrm{T}_{\mathrm{w} 1}+\mathrm{T}_{\mathrm{w} 2}+\mathrm{T}_{\mathrm{w} 3}+\mathrm{T}_{\mathrm{w} 4}+\mathrm{T}_{\mathrm{w} 5}\right) / 5$

The average Nusselt number was specified by:

$N u=\left(\frac{h_{n f} d i}{K_{n f}}\right)$

where $K_{n f}$ is the thermal conductivity of the nanofluid.

Friction factor was calculated using Darcy-Weisbach given by [30,31]:

$$
f=\left(\frac{2 \Delta P}{\rho_{n f} u^{2}\left(\frac{L}{d i}\right)}\right)
$$

where " $u$ " is velocity of fluid, " $L$ " is length of the receiver tube, and $\Delta \mathrm{P}$ is pressure drop of the solar PTC receiver tube.

The correlated collector efficiency of the solar PTC was expressed by:

$$
\eta_{c c}=f\left(\operatorname{Re}, \operatorname{Pr},(1+\phi), I, T_{i}, T_{o}\right)
$$

To validate the heat transfer potency of the solar PTC with nanofluids, a correlation was obtained from experimental data. The mean Nusselt number was calculated based on the equation of Mwesigye et al. [20] for solar trough collector absorber tube, given by:

$$
N u=0.0104 \operatorname{Re}^{0.885} \operatorname{Pr}^{0.374}
$$

To confirm the heat transfer performance of the solar PTC with GO \& $\mathrm{TiO}_{2}$ nanofluids, correlations were developed from experimental results. The Nusselt number correlation as suggested by Pak and Cho [29] was given as:

$$
N u=0.021 \operatorname{Re}^{0.8} \operatorname{Pr}^{0.5}
$$

The results of the correlation equation were compared with those of other significant investigators. The friction factor correlation was adopted from Mwesigye et al. [20] for a solar

PTC absorber tube, given by:

$$
f=0.173 R e^{-0.1974}
$$

Another important friction factor correlation for smooth tubes was adopted from Petukhov's correlation [31], given by:

$$
f=\left(0.790 \ln R e^{-1.64}\right)^{-2}
$$


To estimate uncertainties in results, an approach described by Coleman and Steele [32] was applied. The maximum uncertainty of the collector efficiency was estimated as $1.153 \%$. The deviations in uncertainty were $3.536 \%, 3.101 \%$, and $4.358 \%$ for Reynolds number, Nusselt number, and friction factor, respectively. A brief uncertainty analysis is provided in the supplementary section of this paper.
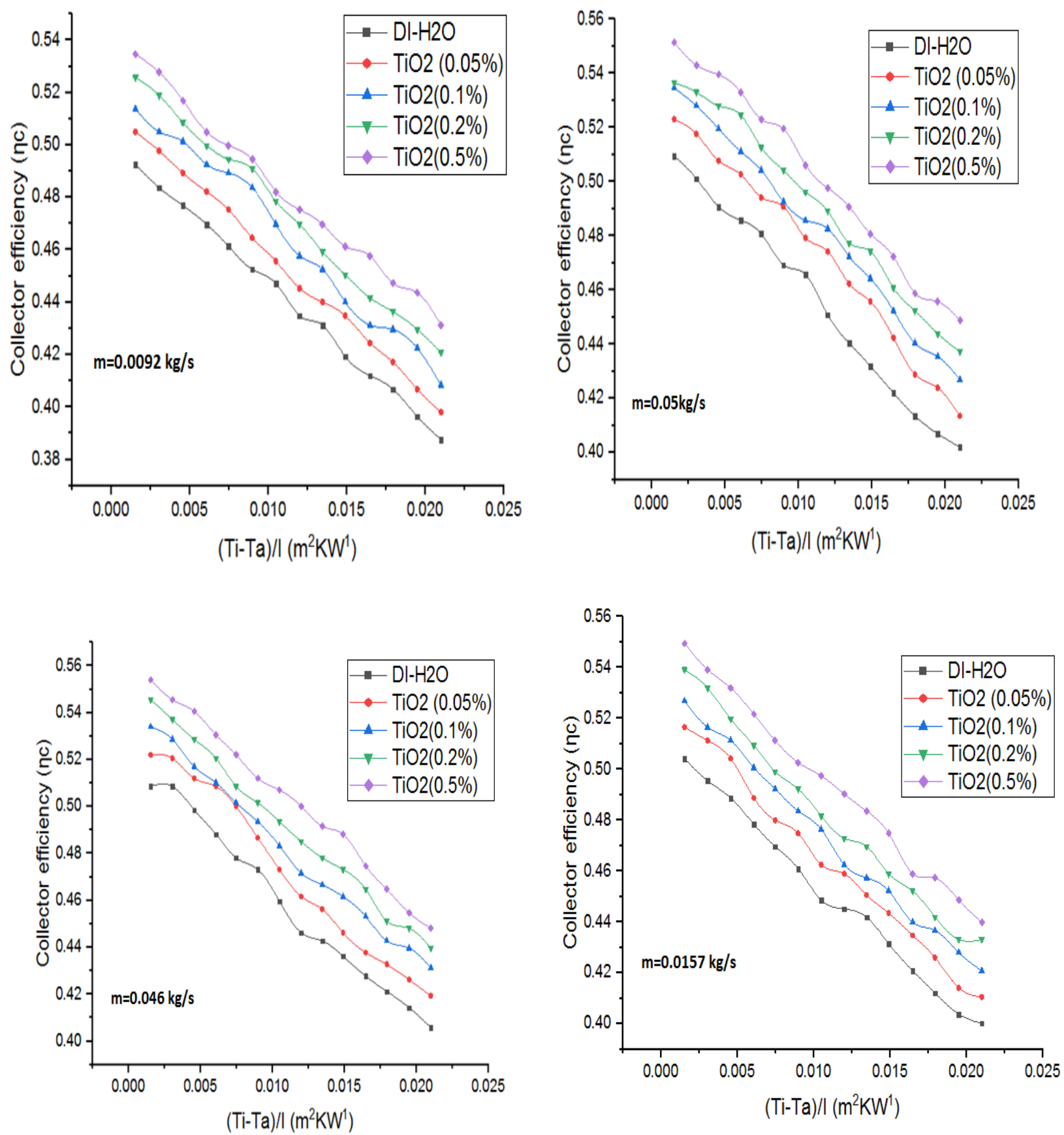

Figure 6 (a-d) : Characteristic curves of solar PTC versus collector efficiency with various flow rates of $\mathrm{TiO}_{2}$ nanofluids. 
Experimental Investigation on Solar Parabolic Trough Collector Performance using Graphene and Titanium Oxide Nanofluids Under Forced Circulation
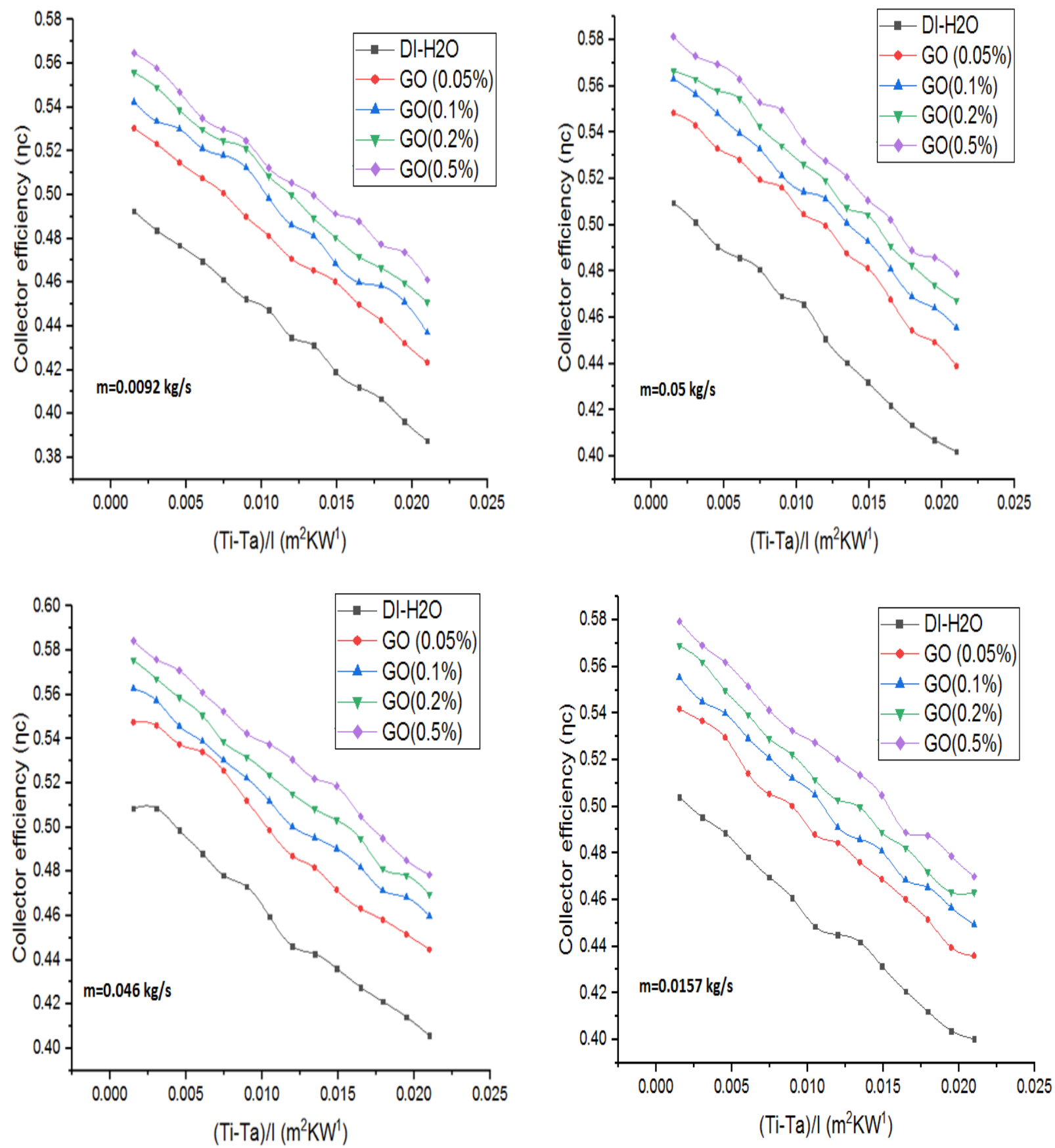

Figure 7 (a-d) : Characteristic curves of solar PTC versus collector efficiency with various flow rates of GO nanofluids.

\subsection{Uncertainty Analysis}

Uncertainty estimates were carried out to determine the accuracy of the measured values obtained from the experiments. According to Eq. (4), the experimental uncertainties of the collector efficiency based on [37] can be calculated as:

$$
A U_{\eta i(x)}=\eta_{i} \times \sqrt{\left(\left(\left(\frac{U_{F R}}{F_{R}}\right)^{2}+\left(\frac{U_{U L}}{U_{L}}\right)^{2}+\left(\frac{U_{\Delta T i a}}{\Delta T_{i a}}\right)^{2}+\left(\frac{U_{G T}}{G_{T}}\right)^{2}\right)\right)}
$$

Where $U_{F R}, U_{U L}, U_{\Delta T i a}$ and $U_{G T}$ are, respectively, the uncertainities of $F_{R}, U_{L}, \Delta T_{i a}$, and $G_{T}$. 


$$
\mathrm{U}_{\mathrm{UL}} / \mathrm{U}_{\mathrm{L}} \leq 2.32 \%, \mathrm{U}_{\mathrm{GT}} / \mathrm{G}_{\mathrm{T}} \leq 3 \%, \mathrm{U}_{\Delta \mathrm{Tia}} / \Delta \mathrm{T}_{\mathrm{ia}} \leq 0.3 \% \text {, and } \mathrm{U}_{\mathrm{FR}} / \mathrm{F}_{\mathrm{R}} \leq 4.21 \% \text {. }
$$

The maximum uncertainty in determining the collector efficiency estimated in the present study was found to be $5.67 \%$. $\left(\mathrm{F}_{\mathrm{R}} \eta_{\mathrm{o}}\right)$

\section{RESULTS AND DISCUSSION}

Figure 5a-d \&6 a-d shows the characteristic curves of the solar PTC versus collector efficiency of nanofluids at various concentrations ranging from $0.05 \%$ to $0.5 \%$ and flow rate conditions.

The stability of GO/DI- $\mathrm{H}_{2} \mathrm{O} \& \mathrm{TiO}_{2} / \mathrm{DI}-\mathrm{H}_{2} \mathrm{O}$ was verified prior to the each cycle test at various flow rates. According to the figure, as heat loss parameter $\left(T_{i}-T_{a}\right) / I$ decreases, collector efficiency $\left(\eta_{c}\right)$ increases for water as well as nanofluids at various concentrations. A maximum collector efficiency of $53.76 \%$ was obtained at $\phi=0.5 \%$ of GO nanofluid, when the mass flow rate was minimum at $0.0092 \mathrm{~kg} / \mathrm{s}$. The trend continued for an increase in mass flow rate of nanofluid from 0.0092 to $0.050 \mathrm{~kg} / \mathrm{s}$. The collector efficiency increased to $54.95 \%, 55.56 \%$, and $55.87 \%$ when the mass flow rate increased to $0.0157,0.046$, and $0.05 \mathrm{~kg} / \mathrm{s}$, respectively. Such an increase in collector efficiency was due to a higher degree of particle absorption, also reduced temperature gradient had a major role in this phenomenon, which was around $58 \%$ to that of water. Moreover, when volume concentration of the nanofluid increased from $0.05 \%$ to $0.5 \%$, there was an appreciable increase in collector efficiency, ranging from $3.36 \%$ to $7.79 \%$, due to radiation absorption ability of nanoparticles in the nanofluid. Characteristics such as absorbed energy parameter $F_{R}(\tau \alpha)$ and removed energy parameter $F_{R}\left(U_{L}\right)$ were measured through experimental results. Based on experimental results, the maximum collector efficiency of $45.23-55.87 \%$ was attained for $\mathrm{GO} / \mathrm{DI}-\mathrm{H}_{2} \mathrm{O}$ nanofluid at $0.5 \%$ concentration. This was because an increase in flow rate inversely decreased the temperature gradient of solar PTC, leading to enhanced efficiency of solar PTC. As another significant argument regarding GO nanoparticles in the working fluids, thermal resistance decreased and subsequently heat transfer coefficient raised, owing to thermal conductivity of nanofluid. For the $\mathrm{TiO}_{2}$ nanofluid at a flow rate of $0.05 \mathrm{~kg} / \mathrm{s}, F_{R}(\tau \alpha)$ and $F_{R}\left(U_{L}\right)$ were estimated at 0.5659 and 7.282 , respectively as shown in fig $8(\mathrm{a} \& \mathrm{~b})$. For the $\mathrm{GO}$ nanofluid at a flow rate of $0.05 \mathrm{~kg} / \mathrm{s}, F_{R}(\tau \alpha)$ and $F_{R}\left(U_{L}\right)$ were estimated at 0.6359 and 7.382 , respectively as shown in fig 8 (a \& b).
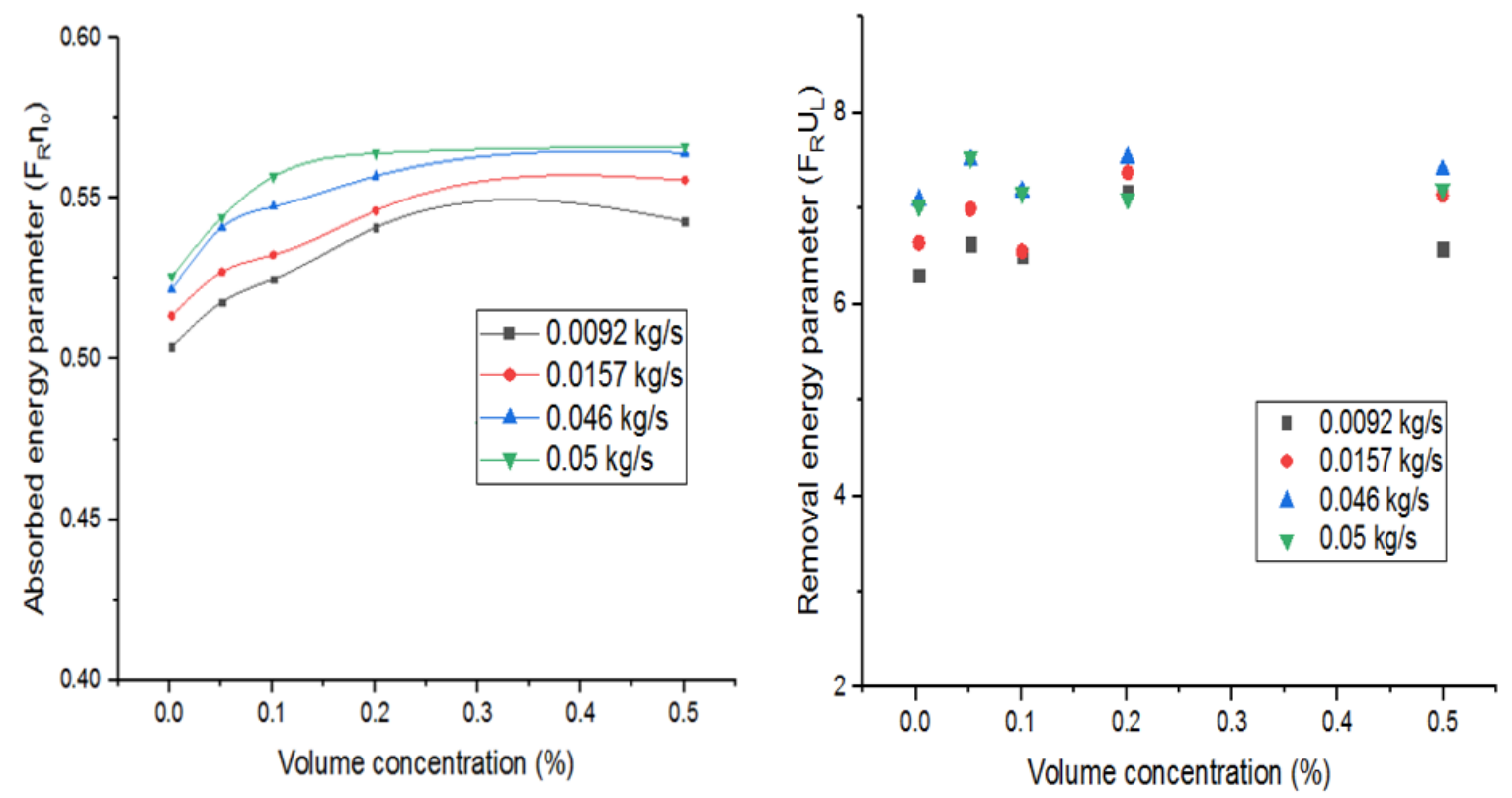

Figure $8(a \& b)$ Volume concentration versus absorbed energy and removal energy at various mass flow rates of $\mathrm{TiO}_{2}$ 
Experimental Investigation on Solar Parabolic Trough Collector Performance using Graphene and Titanium Oxide Nanofluids Under Forced Circulation

The variations in $F_{R}(\tau \alpha)$ over different nanoparticle concentrations $(\phi)$ under different mass flow rates are plotted in Figure 9a. Accordingly, absorbed energy $F_{R}(\tau \alpha)$ grew with increase in nanoparticle volume concentration $(\phi=0.5 \%)$ and reached the maximum at a flow rate of 0.05 $\mathrm{kg} / \mathrm{s}$. The maximum absorbed energy was found to be 0.6359 and the lowest value was equal to 0.5856 , which is for the base fluid. The absorbed energy improves the flow rate as well as the concentration of nanoparticles in the working fluid, since it is a function of mass flow rate, thermal conductivity, and specific heat capacity of the working fluid. Figure $9 \mathrm{~b}$ illustrates the changes in removal energy against the volume concentrations $(\phi)$ at different flow rates. At the maximum flow rate, the removal energy was equal to 6.0428 for $0 \%$ concentration, whereas it was equal to 5.3194 when the flow rate was minimum. It was also remarkably noticed that the removed energy had an inverse correlation with flow rate.
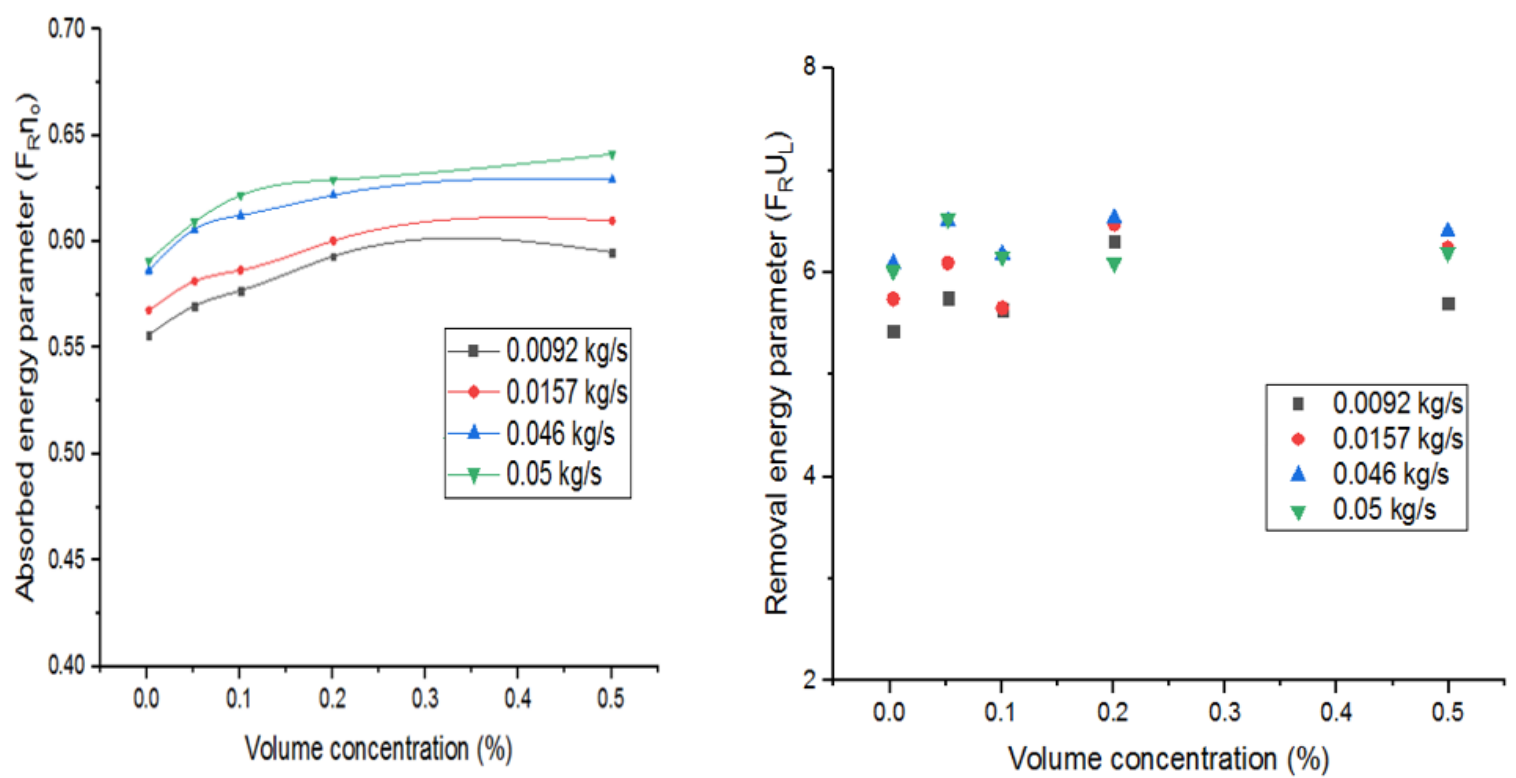

Figure $9(\mathrm{a} \& \mathrm{~b})$ Volume concentration versus absorbed energy and removal energy at various mass flow rates of GO.
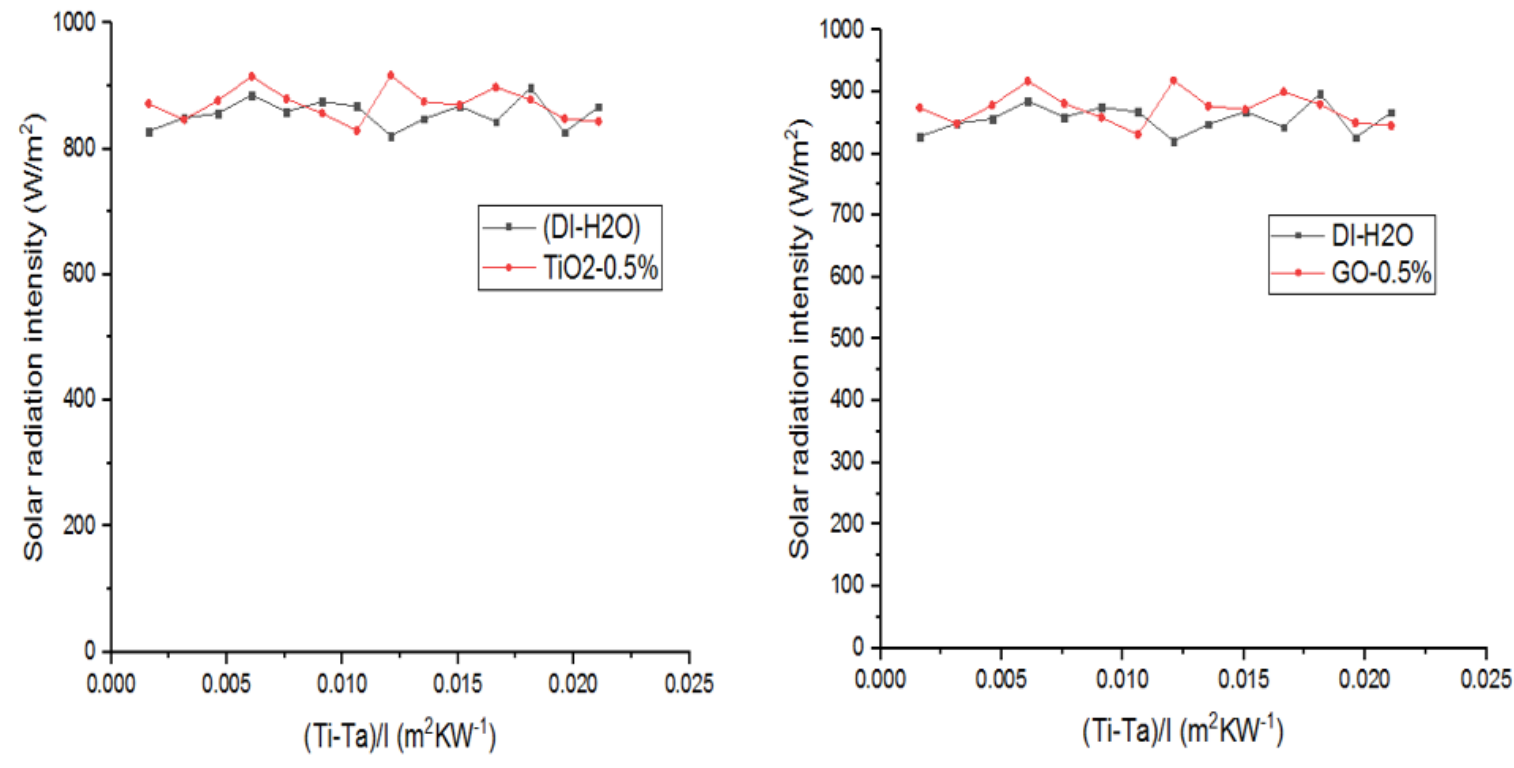

Figure $10(a \& b)$ Variations in solar intensity and useful heat gain with respect to heat loss. 

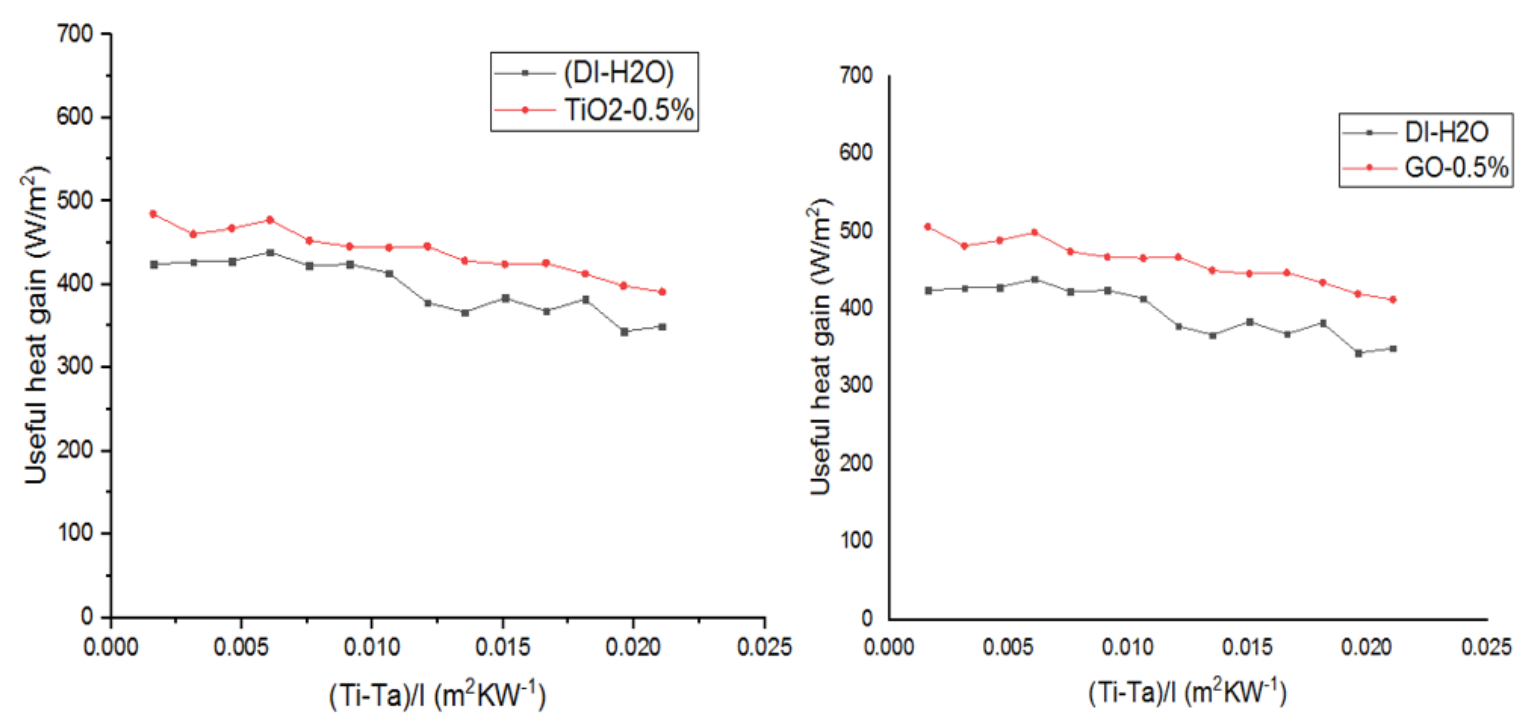

Figure $11(a \& b)$ Variations in useful heat gain with respect to heat loss.

Furthermore, for the nanofluid with a lower velocity in the solar PTC, the heat dissipation rate increased and subsequently energy removal also increased. However, removal energy was approximately within the region at various flow rates and volume concentrations. The overall heat transfer coefficient $\left(U_{L}\right)$ is a function of both internal and external convective heat transfer of the receiver tube. The external surface of receiver tube had a lower convection coefficient and hence the internal convective coefficient did not play any significant role in this phenomenon, whereas, at the outer surface of receiver tube, convection coefficient was constant or negligible as flow rate and volume concentration increased. This may be attributed to the decrement of heat loss from the tube, and it was proportional to the concentration of nanoparticles in the working fluid. With the addition of nanoparticles, heat loss rate was less between the tube and ambient air due to a reduction in tube surface temperature as stated by Mwesigye et al. [20]. The collector efficiency is inversely proportional to the surface temperature and heat loss of the collector. In addition, heat transfer is prone to increase with the addition of nanoparticles, due to the thermophysical properties of nanofluids. Pressure gradient is a function of friction factor and nanofluid velocity, which causes an enhancement of pumping power. The pressure gradient is higher at the maximum flow rate and nanoparticle concentration. The maximum pressure drop attained at $0.5 \%$ concentration was due to surface collision by the nanoparticles and Brownian motion particle interface and interchangeability between fluid and surface boundaries. The increase in gradient pressure was due to the adding up of nanoparticles in the working fluid, leading to an increase in nanofluid viscosity. Hence, at a higher volume concentration of $(\phi=0.5 \%)$, the maximum pressure drop of $79.52 \mathrm{kPa} / \mathrm{m}$ was attained, leading to the maximum pumping power of $0.0116 \mathrm{~W} / \mathrm{m}$. Nevertheless, it could be overcome by enhancing heat transfer through an appropriate addition of nanoparticles and a suitable design. Figure 10 shows the variation in useful heat gain with respect to heat loss, considering maximum volume concentration and flow rate of $0.5 \%$ and $0.05 \mathrm{~kg} / \mathrm{s}$, respectively. A maximum heat gain of $510 \mathrm{~W} / \mathrm{m}^{2}$ can be attained by way of addition of GO nanoparticles to the base fluids. It was due to this reason that thermal resistance decreased while convective heat transfer coefficient increased due to a higher thermal conductivity of nanofluids. In the end, an efficiency of up to a maximum value of $59.87 \%$ was achieved for the present solar PTC. 
Experimental Investigation on Solar Parabolic Trough Collector Performance using Graphene and Titanium Oxide Nanofluids Under Forced Circulation
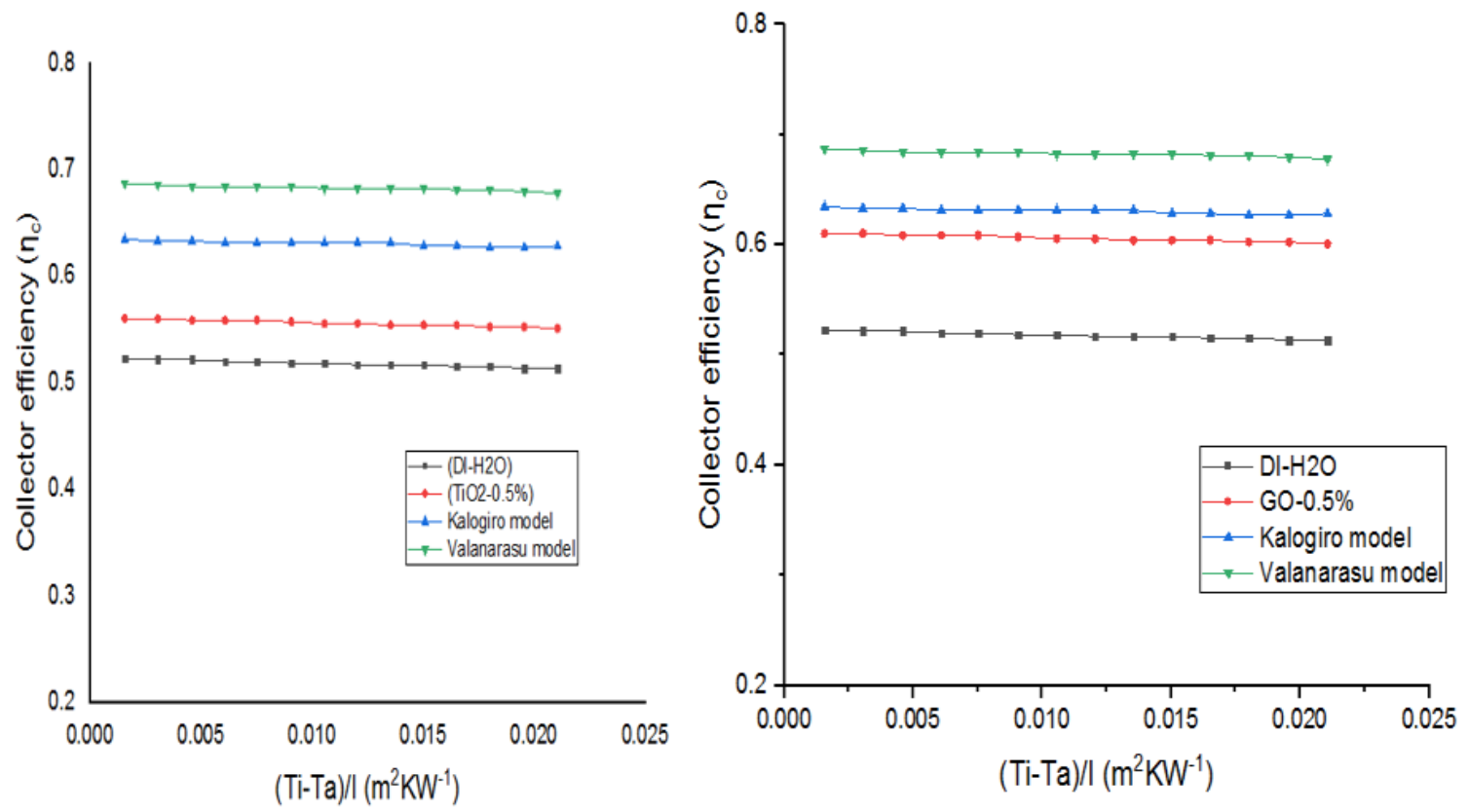

Figure $12(\mathrm{a} \& \mathrm{~b})$ Characteristics curves of solar PTC versus collector efficiency for the different models.

The addition of nanoparticles to $\mathrm{DI} / \mathrm{H}_{2} \mathrm{O}$ much improved heat gain of the nanofluid as compared to plain water. It was due to this reason that the shorter wavelength of nanoparticles enhanced the absorption of nanofluids. In addition, as the size of nanoparticles was less than 50 $\mathrm{nm}$, a negligible scattering took place, which enhanced the heat gain of nanofluids.

This observation was in accordance with an earlier study [22]. The variation of heat loss parameter $\left(T_{i}-T_{a}\right) /$ I over collector efficiency $\left(\eta_{c}\right)$ in the present model was compared with base fluid models as depicted in Figure 12. The present model was tested based on ASHRAE standards. The collector efficiency was plotted against heat loss parameter versus collector efficiency with respect to intercept factor of $F_{R}\left(U_{L}\right)$ and slope factor of $F_{R}(\tau \alpha)$ using linear regression fit method. The maximum achievable collector efficiency in the present model at a volume concentration $\phi=0.5 \%$ was about $57.31 \%$. Based on the present collector model, the average overall heat transfer coefficient $\left(U_{L}\right)$ was $9.52 \mathrm{~W} / \mathrm{m}^{2} \mathrm{~K}$. The collector efficiency at a nanofluid volume concentration of $0.5 \%$ enhanced by $9.5 \%$ as compared to that of the base fluid (DI water).

Figure 13 shows that the temperature gradient of pure DI water is higher, when $\Delta \mathrm{T}$ is equal to $28.52^{\circ} \mathrm{C}$ at a minimum mass flow rate of $0.0092 \mathrm{~kg} / \mathrm{s}$. At the same flow rate, temperature gradient for a maximum concentration of nanoparticles of $\phi=0.5 \%$ is $15.56^{\circ} \mathrm{C}$, which is $48.22 \%$ lower than that of water. As mass flow rate of nanofluid increases, temperature gradient reduces for both pure DI water as well as nanofluid. It was due to this reason that at a higher flow rate, the interaction of fluid with inner wall surface was less, which may have led to the reduction of temperature gradient for both the fluids. Moreover, for the nanofluid, thermal resistance was effectively reduced in the solar PTC system. Figure 14 shows the variations in collector efficiency against different mass flow rates of water as well as $\phi=0.5 \%$ of nanofluid. The addition of GO nanoparticles led to an increase in collector efficiency from $49 \%$ to $55.87 \%$. The collector efficiency also increased as the mass flow rate of the fluid increased from 0.0092 to $0.05 \mathrm{~kg} / \mathrm{s}$. It is interesting to note that such an increase in collector efficiency took place in three stages: (i) increase at a faster rate between 0.0092 and $0.0157 \mathrm{~kg} / \mathrm{s}$, (ii) gradual increase between 0.0157 and $0.046 \mathrm{~kg} / \mathrm{s}$, (iii) asymptotic trend beyond a mass flow rate of 0.046-0.05 
$\mathrm{kg} / \mathrm{s}$. The enhancement of collector efficiency was due to higher thermal conductivity and higher extinction coefficient of nanoparticles, whose shorter wavelengths cause absorption of more than 65\% inward solar energy [22]. Thus, under the same operating conditions, the efficiency of nanofluid-based solar collector was higher as compared to that of the base fluid (DI water). The deviation between experimental and correlated values of Nusselt number at various mass flow rates and volume concentrations is shown in Figure 15, and the maximum error observed was $65.35 \%$ corresponding to the higher Reynolds number. The correlation for Nusselt number of the solar PTC absorber tube with nanofluids at various concentrations $(0.05-$ $0.5 \%)$ was specified as a range of Reynolds number $(2410 \leq \mathrm{Re} \leq 7230)$ and Prandtl number $(2.18 \leq \operatorname{Pr} \leq 5.77)$, as determined from Eq. (19):

$$
N u_{c}=0.021386(R e)^{0.702}(P r)^{0.527}(1+\phi)^{1.658}
$$
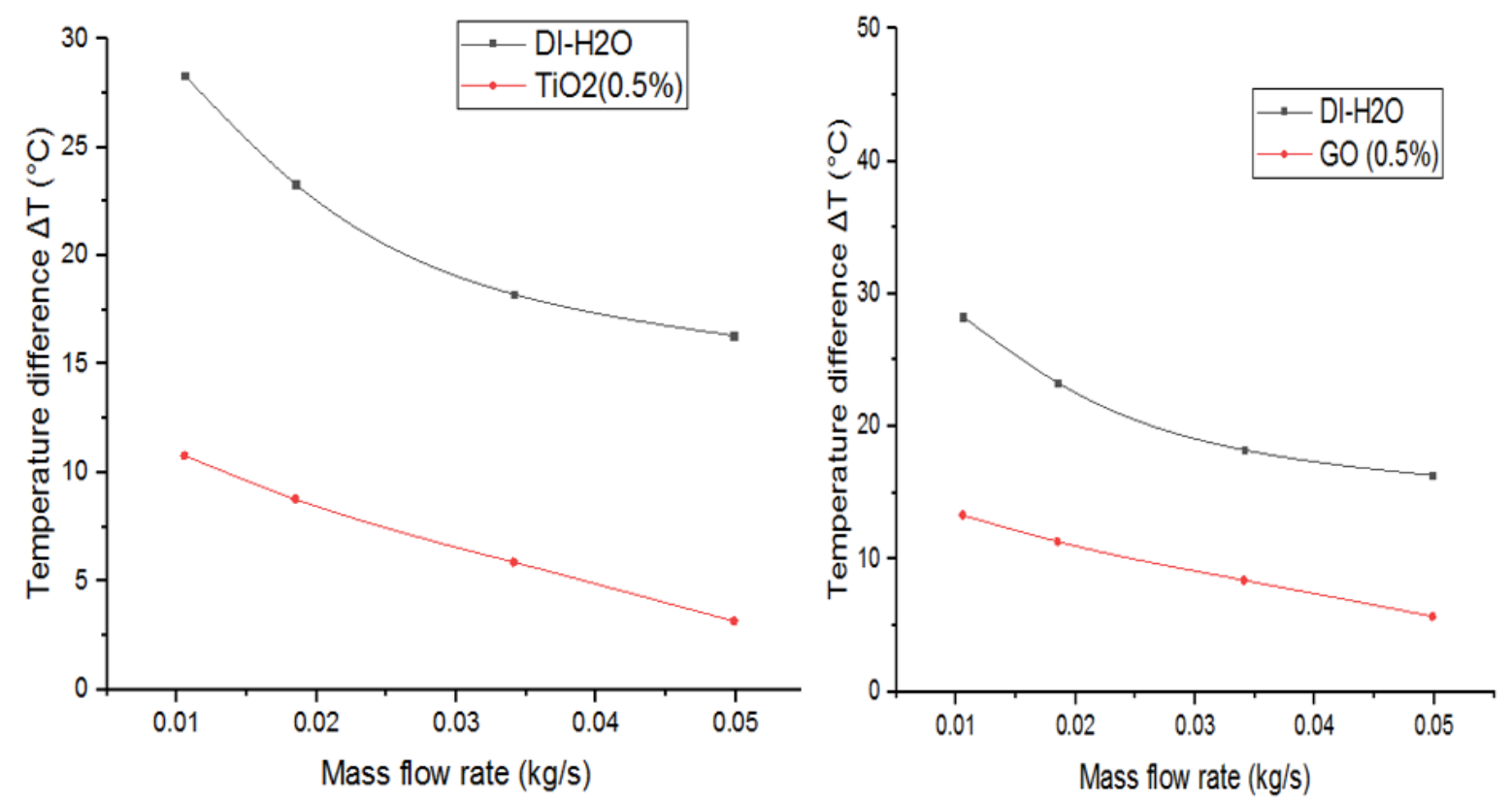

Figure $13(a \& b)$ Variations of mass flow rate with temperature differences
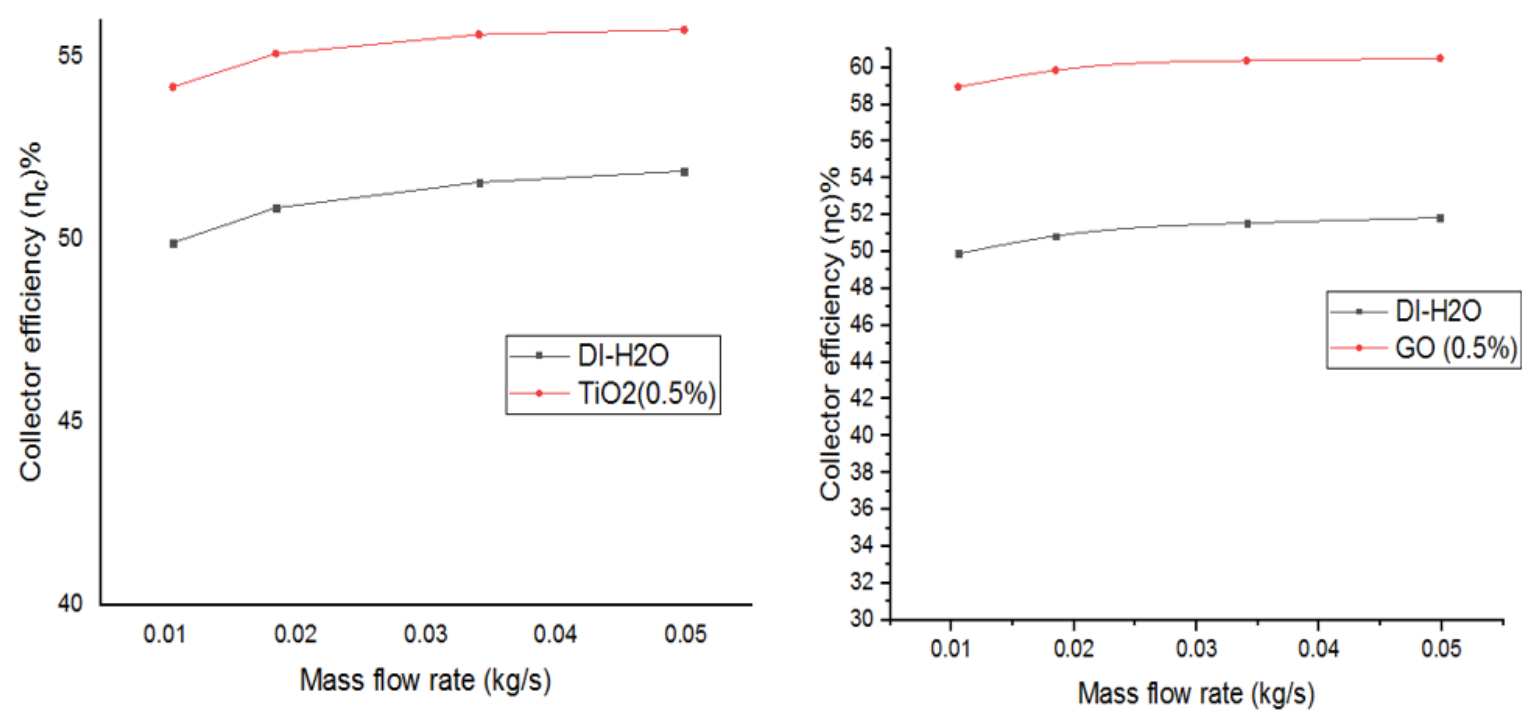

Figure $14(a \& b)$ Variations of mass flow rate with different collector efficiencies. 
Experimental Investigation on Solar Parabolic Trough Collector Performance using Graphene and Titanium Oxide Nanofluids Under Forced Circulation

The $\mathrm{R}^{2}$ value was equal to 0.9895 . The peak Nusselt number was attained for the nanoparticle volume concentration of $\phi=0.5 \%$, as compared to the base fluid. This was due to the thermal conductivity of nanoparticles and also the heat transfer augmentation correlated with chaotic nanoparticle behaviors in receiver tube surface, promoting higher convective heat transfer.

Figure 16 shows the variations in friction factor with experimental and predicted values of nanoparticles at different volume concentrations. The receiver tube friction factor is a function of pressure drop, Reynolds number, and receiver tube wall roughness as shown in Eq. (20). The friction factor of the solar PTC absorber tube with nanofluids of various concentrations $(0.05-$ $0.5 \%$ ) was determined as:
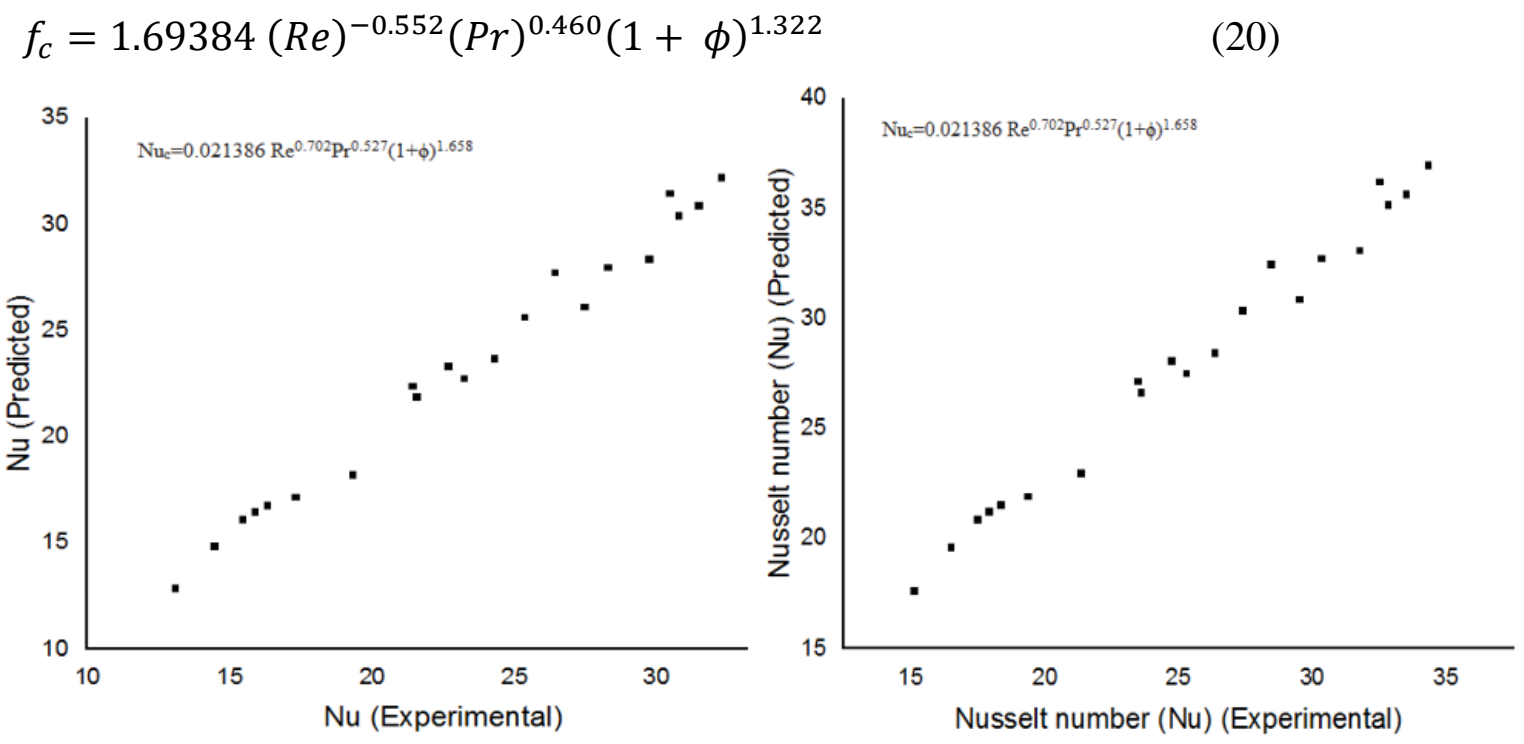

Figure $15(a \& b)$ Variations in predicted and experimental Nusselt number with respect to Reynolds number.
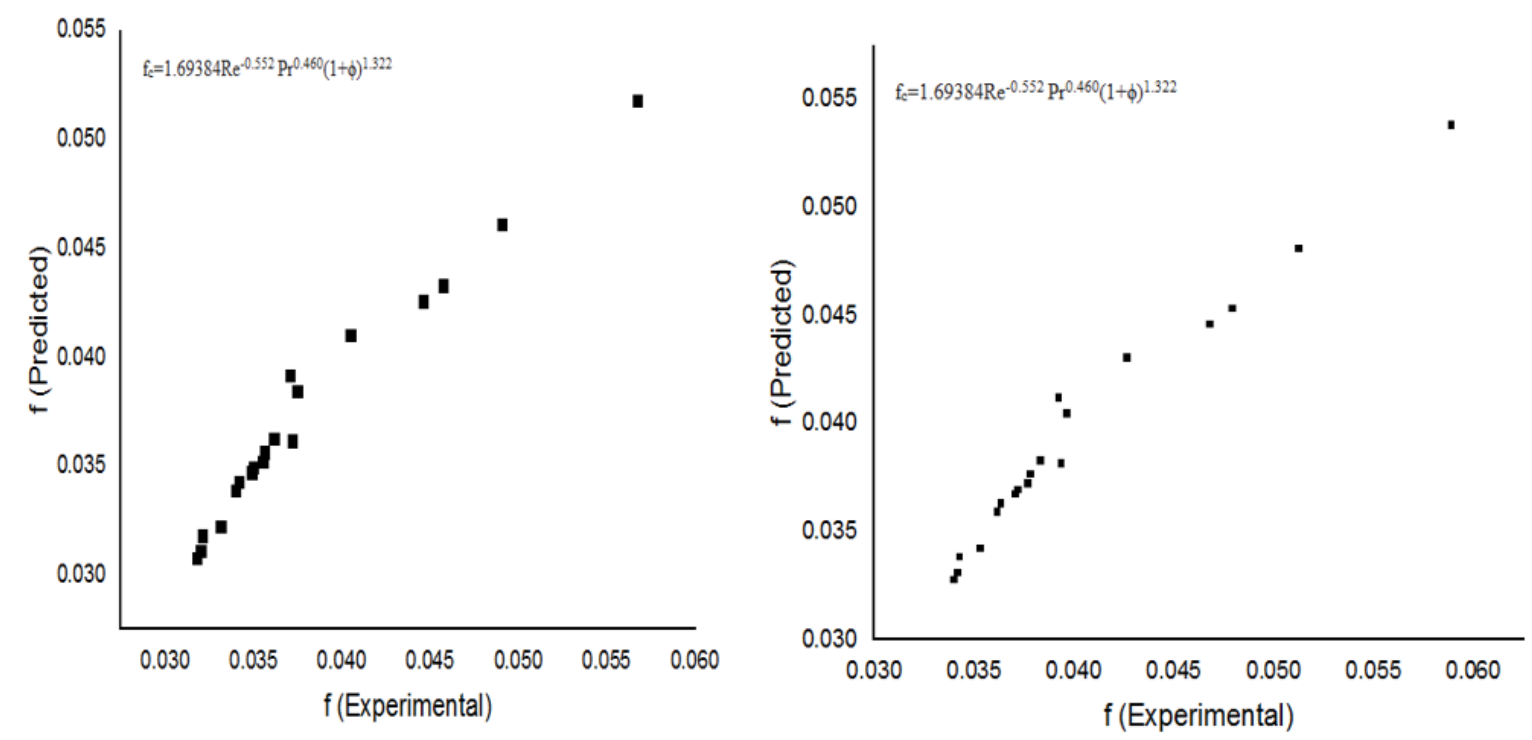

Figure $16(a \& b)$ Comparison of friction factor between experimental and predicted values. 
The corresponding $\mathrm{R}^{2}$ value was equal to 0.995 . The deviations between experimental and correlated values of friction factor were in the range of $19.35 \%$ to $29.61 \%$. In general, the nanofluid with a higher volume concentration will enhance heat transfer, but results in increased fluid friction due to higher viscosity and pressure gradient.
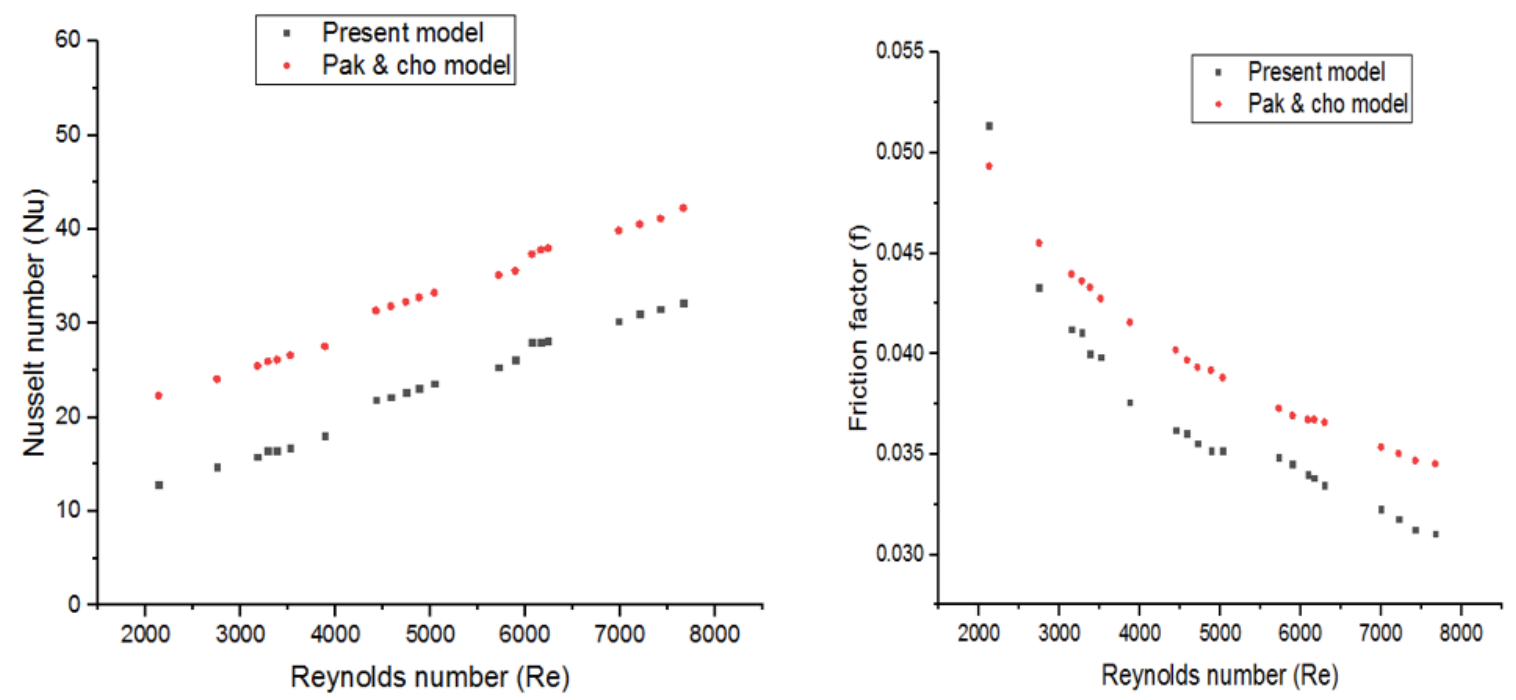

Figure 17 (a \& b) Validation of present study results against existing correlations in literature

For the present model, a validation was carried out for Nusselt number and friction factor with respect to Reynolds number and compared with previous studies Figure 17. The comparison showed that the trend of present model follows earlier models. The other models reported a higher range of Nusselt number $(4500 \leq \mathrm{Re} \leq 7201)$, which may be due to the chaotic motion of nanoparticles near the absorber wall, there by declining boundary layer thickness [34]. The comparison study based on friction factor for varying Reynolds number shows that the present results are in good agreement with earlier models. The study shows that there was a minor deviation in trend for friction factor up to Reynolds number equal to 6500. Moreover, the study shows that the friction factor reduces by the increasing the flow rate of the nanofluid as the results of thinner laminar sub layer near the inner wall of the tube and lower thermal resistance at core of the absorber tube.
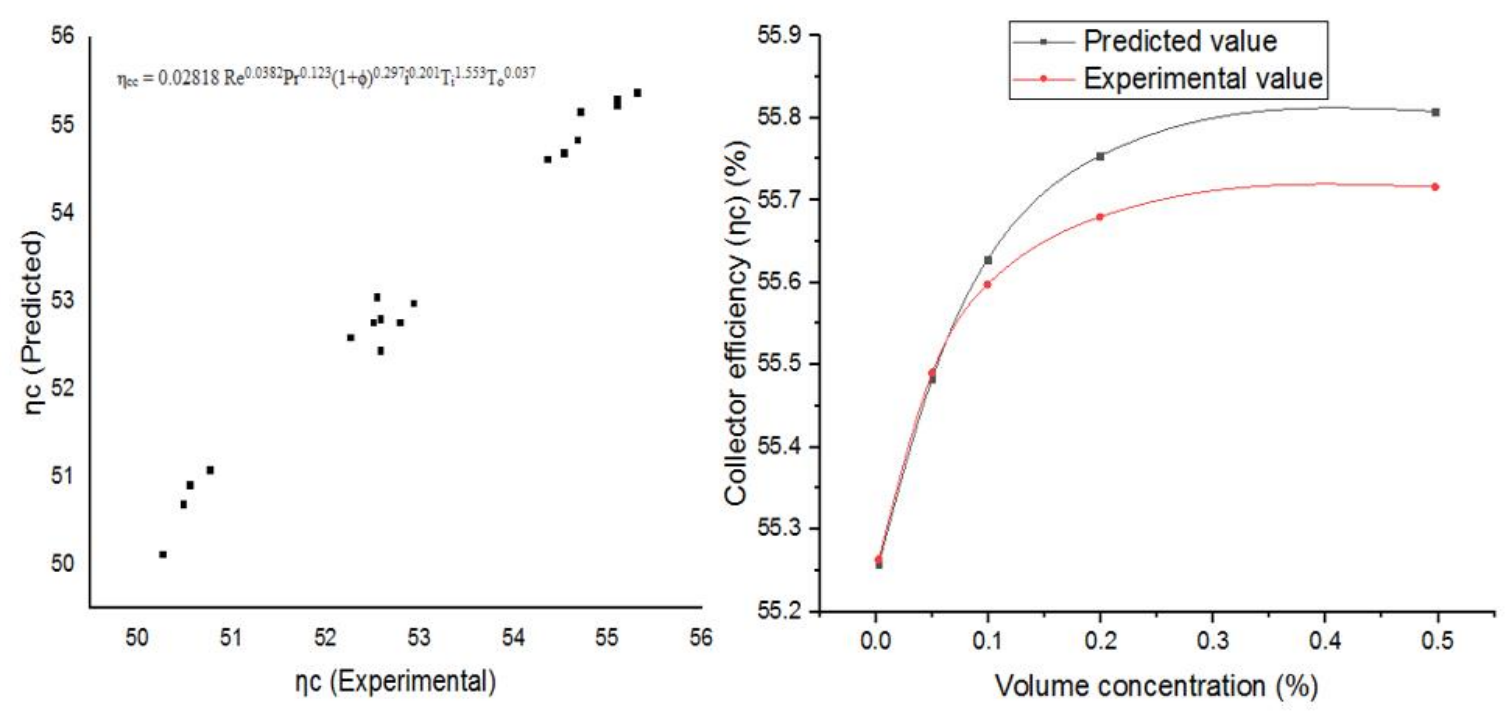

Figure $18(a \& b)$ Variations in experimental efficiency over correlated efficiency. 
Experimental Investigation on Solar Parabolic Trough Collector Performance using Graphene and Titanium Oxide Nanofluids Under Forced Circulation

Figure 18 shows the validation of experimental results with predicted values for collector efficiency. The collector efficiency is a function of parameters such as Reynolds number, Prandtl number, nanoparticle concentration ratio, radiance absorbed, inlet temperature, and outlet temperature. The correlation results show that collector efficiency is the good agreement with experimental results.

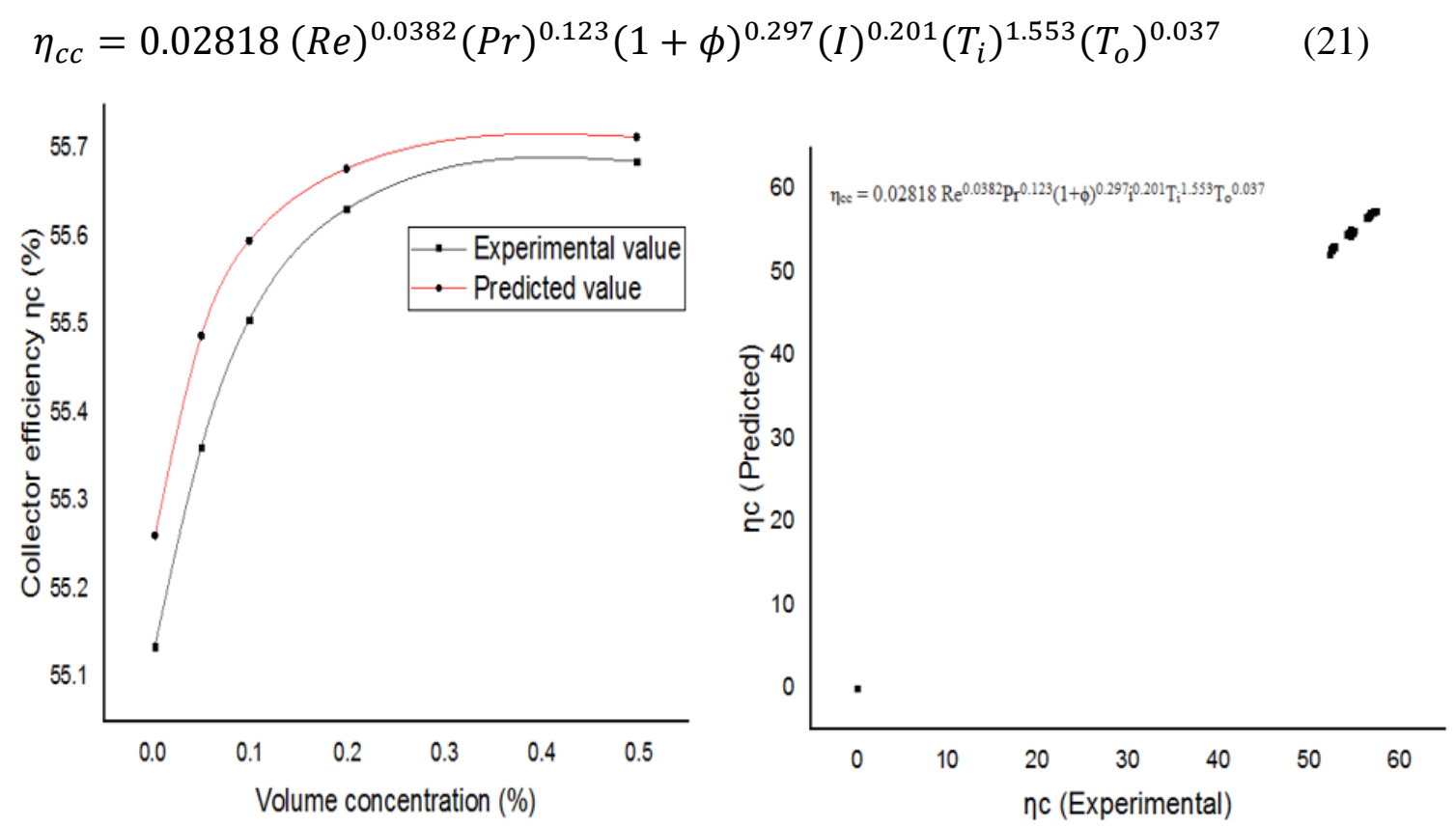

Figure $19(a \& b)$ Comparison of collector efficiency across various volume concentrations.

The above correlation was carried out for collector efficiency with nanofluids of various volume concentrations, given by Eq. (21). The deviation in collector efficiency was very minimal at $\pm 1.02 \%$ based on the $\mathrm{R}^{2}$ value of correlation equal to 0.995 . Figure 19 shows the correlation results of collector efficiency for volume concentrations in the range of $0 \leq \phi \leq$ $0.5 \%$. The correlation results show that collector efficiency increased as volume concentration increased up to $0.2 \%$, behind which it maintained almost an asymptotic trend. A similar trend was maintained for experimental as well as predicted values. The reason for the increase in collector efficiency was due to a reduction in absorption tube temperature as well as radiation losses at higher volume concentrations. The increase in collector efficiency was from $49 \%$ to $56 \%$ at a volume concentration of $0.5 \%$. Also, the experimental values of collector efficiency had an excellent agreement with correlated values.

\section{CONCLUSIONS}

- A maximum collector efficiency up to $55.84 \%$ was achieved at a maximum mass flow rate and volume concentration ( $\mathrm{m}=0.05 \mathrm{~kg} / \mathrm{s}$ and $\phi=0.5 \%)$ with GO nanofluid.

- Collector efficiency is absorbed energy parameter in the range of 0.5049-0.5669 for the varying concentrations of graphene nanofluid. Another significant parameter, removal energy parameter, was in the range of 6.457-6.782 for various concentrations of graphene nanofluids.

- The efficiency of solar trough collector was enhanced from $3.68 \%$ to $8.74 \%$ by the addition of graphene nanoparticles to base fluid.

- The maximum collector efficiency was achieved at $\phi=0.5 \%$ concentration, while the efficiency curve showed an asymptotic trend after $\phi=0.2 \%$ concentration. The parametric study results 
suggest that a lower volume concentration $(\phi=0.2 \%)$ of graphene is optimal for solar PTC experiments.

A comprehensive multiple regression equation is developed with the experimental data for the evaluation of Nusselt number, friction factor and collector efficiency with PTC absorber tube as:

$$
\begin{gathered}
N u_{c}=0.021386(\operatorname{Re})^{0.702}(\operatorname{Pr})^{0.527}(1+\phi)^{1.658} \\
f_{c}=1.69384(\operatorname{Re})^{-0.552}(\operatorname{Pr})^{0.460}(1+\phi)^{1.322} \\
\eta_{c c}=0.02818(\operatorname{Re})^{0.0382}(\operatorname{Pr})^{0.123}(1+\phi)^{0.297}(I)^{0.201}\left(T_{i}\right)^{1.553}\left(T_{o}\right)^{0.037}
\end{gathered}
$$

\section{NOMENCLATURE}

$\mathrm{A}_{\mathrm{a}}$

$\mathrm{C}_{\mathrm{p}}$

$d$

$d_{i}$

$f$

$f$

$h$

$I$

$I_{g}$

K

$K_{\alpha \tau}$

$L$

$m$

$\mathrm{Nu}$

$\mathrm{Pr}$

$\Delta \mathrm{P}$

$\mathrm{Q}_{\text {in }}$

Re

$S$

$T_{i}$

$T_{o}$

$T_{f o, s s}$

$\Delta \mathrm{T}$

$u$

$W$

ASHRAE

PTC

SFPC

$S S A$

IAM
Aperture area $\left(\mathrm{m}^{2}\right)$

Specific heat capacity $(\mathrm{kJ} / \mathrm{kg} \mathrm{K})$

Depth of the parabola reflector $(\mathrm{m})$

Receiver tube inner diameter (m)

Friction factor

Parabola focal distance (m)

Convective heat transfer coefficient $(\mathrm{W} / \mathrm{m} 2 \mathrm{~K})$

Direct normal irradiance $(\mathrm{W} / \mathrm{m} 2)$

Solar radiation intensity $(\mathrm{W} / \mathrm{m} 2)$

Thermal conductivity (W/m K)

Incidence angle modifier

Length of the receiver tube $(\mathrm{m})$

Mass flow rate $(\mathrm{kg} / \mathrm{s})$

Nusselt number

Prandtl number

Pressure drop of the fluid in $(\mathrm{Pa})$

Useful heat gain (W)

Reynolds number

Are length of the parabola (m)

Inlet temperature of the working fluid $\left({ }^{\circ} \mathrm{C}\right)$

Outlet temperature of the working fluid $\left({ }^{\circ} \mathrm{C}\right)$

Steady state working fluid outlet temperature $\left({ }^{\circ} \mathrm{C}\right)$

Temperature gradient of fluid $\left({ }^{\circ} \mathrm{C}\right)$

Working fluid velocity $(\mathrm{m} / \mathrm{s})$

Parabola aperture length $(\mathrm{m})$

American Society of Heating, Refrigeration and Air-conditioning Engineers

Parabolic Trough Collector

Solar Flat Plate Collector

Specific Surface Area

Incident Angle Modifier 
Experimental Investigation on Solar Parabolic Trough Collector Performance using Graphene and Titanium Oxide Nanofluids Under Forced Circulation
$D I$
Deionized water
$G O$
Graphene
$\mathrm{TiO}_{2}$
Titanium oxide

\section{Greek Symbols}

$\begin{array}{ll}\mu & \text { Dynamic viscosity }\left(\mathrm{Ns} / \mathrm{m}^{2}\right) \\ \rho & \text { Density }\left(\mathrm{kg} / \mathrm{m}^{2}\right) \\ \phi_{\mathrm{r}} & \text { Rim angle }\left(^{\circ}\right) \\ \phi & \text { Volume concentration }(\%) \\ \Theta_{\mathrm{a}} & \text { Half acceptance angle }\left(^{\circ}\right) \\ \eta_{\mathrm{c}} & \text { Collector efficiency } \\ \eta_{\mathrm{cc}} & \text { Correlated collector efficiency } \\ \tau_{\mathrm{o}} & \text { Solar time constant }(\mathrm{s})\end{array}$

\section{Subscripts}

$\begin{array}{ll}b f & \text { Base fluid } \\ n f & \text { Nanofluid } \\ p & \text { Nanoparticle }\end{array}$

\section{REFERENCES}

[1] Murshed SMS, Leong KC, Yang C. Thermophysical and electro-kinetic properties of nanofluids - a critical review. Appl Therm Eng 2008;28:2109-25.

[2] Zhu HT, Zhang CY, Liu SQ, Tang YM, Yin YS. Effects of nanoparticle clustering and alignment on thermal conductivities of $\mathrm{Fe}_{3} \mathrm{O}_{4}$ aqueous nanofluids. Appl Phys Lett 2006;89(2):023123.

[3] Kasaeian A, Daviran S, Azarian RD, Rashidi A. Performance evaluation and nanofluid using capability study of a solar parabolic trough collector. Energy Convers Manage 2015;89:36875 .

[4] Aly WI. Numerical study on turbulent heat transfer and pressure drop of nanofluid in coiled tube-in-tube heat exchangers. Energy Convers Manage 2014;79:304-16.

[5] Huminic G, Huminic A. Numerical study on heat transfer characteristics of thermosyphon heat pipes using nanofluids. Energy Convers Manage 2013;76:393-9.

[6] Das SK, Choi SUS, Patel HE. Heat transfer in nanofluids-a review. Heat Transfer Eng 2006;27(10):3-19.

[7] Li XF, Zhu DS, Wang XJ, Wang N, Gao JW, Li H. Thermal conductivity enhancement dependent $\mathrm{pH}$ and chemical surfactant for $\mathrm{Cu}-\mathrm{H} 2 \mathrm{O}$ nanofluids. Thermochim Acta 2008;469(1):98-103.

[8] Chen H, Yang W, He Y, Ding Y, Zhang L, Tan C, et al. Heat transfer and flow behaviour of aqueous suspensions of titanate nanotubes (nanofluids). Powder Technol 2008;183(1):63-72.

[9] Jaisankar S, Radhakrishnan TK, Sheeba KN. Experimental studies on heat transfer and thermal performance characteristics of thermosyphon solar water heating system with helical and left-right twisted tapes. Energy Convers Manage 2011;52:2048-55. 
[10] Lomascolo M, Colangelo G, Milanese M, Risi A. Review of heat transfer in nanofluids: conductive, convective and radiative experimental results. Renew Sustain Energy Rev 2015;43:1182-98.

[11] Hajjar Z, Rashidi AM, Ghozatloo A. Enhanced thermal conductivities of graphene oxide nanofluids. Int Commun Heat Mass Transfer 2014;57:128-31.

[12] Nasiri A, Shariaty-Niasar M, Rashidi AM, Khodafarin R. Effect of CNT structures on thermal conductivity and stability of nanofluid. Int J Heat Mass Transf 2012;55(6):1529-35.

[13] Nanda J, Maranville C, Bollin SC, Sawall D, Ohtani H, Remillard JT, et al. Thermal conductivity of single-wall carbon nanotube dispersions role of interfacial effects. J Phys Chem C 2008;112(3):654-8.

[14] Ding Y, Alias H, Wen D, Williams RA. Heat transfer of aqueous suspensions of carbon nanotubes (CNT nanofluids). Int J Heat Mass Transf 2006;49 (1):240-50.

[15] Yang Y, Zhang ZG, Grulke EA, Anderson WB, Wu G. Heat transfer properties of nanoparticle-in-fluid dispersions (nanofluids) in laminar flow. Int $\mathbf{J}$ Heat Mass Transf 2005;48(6):1107-16.

[16] Lee SW, Kim KM, Bang IC. Study on flow boiling critical heat flux enhancement of Graphene oxide/water nanofluid. Int J Heat Mass Transf 2013;65:348-56.

[17] Yu W, Xie H, Wang X. Significant thermal conductivity enhancement for nanofluids containing graphene nanosheets. Phys Lett A 2011;375 (10):1323-8.

[18] Novoselov KS, Geim AK, Morozov SV, Jiang D, Zhang Y, Dubonos SV, et al. Electric field effect in atomically thin carbon films. Science 2004;306 (5696):666-9.

[19] Balandin AA, Ghosh S, Bao W, Calizo I, Teweldebrhan D, Miao F, et al. Superior thermal conductivity of single-layer graphene. Nano Lett 2008;8:902.

[20] Mehrali M, Sadeghinezhad E, Latibari ST, Kazi SN, Mehrali M, Zubir MNBM, et al. Investigation of thermal conductivity and rheological properties of nanofluids containing Graphene nanoplatelets. Nanoscale Res Lett 2014;9 (1):1-12.

[21] Jyothirmayee ASS, Ramaprabhu S. Surfactant free graphene nanosheets based nanofluids by in-situ reduction of alkaline graphite oxide suspensions. J Appl Phys 2011;110(12):124326.

[22] Yarmand H, Gharehkhani GS, Ahmadi Seyed Shirazi SF, Baradaran S, Montazer E, Mohd Zubir MN, et al. Graphene nanoplatelets - silver hybrid nanofluids for enhanced heat transfer. Energy Convers Manage 2015;100:419-28.

[23] Ghozatloo A, Rashidi A, Shariaty-Niassar M. Convective heat transfer enhancement of graphene nanofluids in shell and tube heat exchanger. Exp Thermal Fluid Sci 2014;53:13641.

[24] Mehrali M, Sadeghinezhad E, Rosenc MA, Akhiani AR, Latibari ST, Mehrali M, et al. Heat transfer and entropy generation for laminar forced convection flow of graphene nanoplatelets nanofluids in a horizontal tube. Int Commun Heat Mass Transfer 2015;66:23-31.

[25] Zanjani HA, Saffar-Avval M, Mansourkiaei M, Sharif F, Ahadi M. Experimental investigation of laminar forced convective heat transfer of graphene water nanofluid inside a circular tube. Int J Therm Sci 2016;100:316-23.

[26] Amiri A, Sadri R, Shanbedi M, Ahmadi G, Chew B, Kazi S. Performance dependence of thermosyphon on the functionalization approaches: an experimental study on thermophysical properties of graphene nanoplatelet based water nanofluids. Energy Convers Manage 2015;92:322-30. 
Experimental Investigation on Solar Parabolic Trough Collector Performance using Graphene and Titanium Oxide Nanofluids Under Forced Circulation

[27] Sadeghinezhad E, Mehrali M, Saidur R, Mehrali Mehdi, Latibari ST, Akhiani AR, et al. A comprehensive review on graphene nanofluids: recent research, development and applications. Energy Convers Manage 2016;111:466-87.

[28] Mahian Omid, Kianifar Ali, Kalogirou Soteris A, Pop Ioan, Wongwises Somchai. A review on the applications of nanofluids in solar energy. Int J Heat Mass Transf 2013;57(2):58294.

[29] Mahian Omid, Kianifar Ali, Sahin Amet Z, Wongwises Somchai. Entropy generation during $\mathrm{Al}_{2} \mathrm{O}_{3}$ /water nanofluid flow in a solar collector: effects of tube roughness, nanoparticle size, and different thermophysical models. Int J Heat Mass Transf 2014;78:64-75.

[30] Mahian Omid, Kianifar Ali, Sahin Ahmet Z, Wongwises Somchai. Performance analysis of a mini channel-based solar collector using different nanofluids. Energy Convers Manage 2014;88:129-38.

[31] Wu TT, Ting JM. Preparation and characteristics of graphene oxide and its thin films. Surf Coat Technol 2013;231:487-91.

[32] Ferrari AC. Raman spectroscopy of graphene and graphite: disorder, electron phonon coupling, doping and non-adiabatic effects. Solid State Commun 2007;143:47-57.

[33] Choi SUS, Zhang ZG, Yu W, Lockwood FE, Grulke EA. Anomalous thermal conductivity enhancement in nanotube suspensions. Appl Phys Lett 2001;79:14.

[34] Rashmi S, Ramaprabhu S. Nitrogen doped hybrid carbon based composite dispersed nanofluids as working fluid for low-temperature direct absorption solar collectors. Sol Energy Mater Sol Cells 2015;140:9-16.

[35] Jang SP, Choi SUS. Role of Brownian motion in the enhanced thermal conductivity of nanofluids. Appl Phys Lett 2004;84:4316.

[36] Wang B, Hao J, Li Q, Li H. New insights into thermal conduction mechanisms of multiwalled carbon nanotube/ionic liquid suspensions. Int J Thermal Sci 2014;83:89-95.

[37] Abernethy RB. ASME measurement uncertainty. ASME J Fluids Eng 1985;107 (2):161-4.

[38] [38] Churchill SW. Correlating equations for heat, mass and momentum transfer in fully developed flow in smooth tubes. Ind Eng Chem Fundam 1977;16:109-16.

[39] Shah RK. Thermal entry length solutions for the circular tube and parallel plates. Paper HMT-11-75, Proceedings of 3rd national heat mass transfer conference Indian institute of technology, vol. 1. Bombay, India, December 11-13; 1975.

[40] Sieder EN, Tate GE. Heat transfer and pressure drop of liquids in tubes. Ind Eng Chem $1936 ; 28$.

[41] Xuan Y, Li Q. Heat transfer enhancement of nanofluids. Int J Heat Fluid Flow 2000;21:5864.

[42] Kamatchi R, Venkatachalapathy S, Abhinaya Srinivas B. Synthesis, stability, transport properties, and surface wettability of reduced graphene oxide/water nanofluids. Int $\mathrm{J}$ Therm Sci 2015;97:17-25. 